\title{
Major investment in active travel in Outer London: Impacts on travel behaviour, physical activity, and health
}

\author{
Rachel Aldred ${ }^{\mathrm{a}, *}$, James Woodcock ${ }^{\mathrm{b}}$, Anna Goodman ${ }^{\mathrm{c}}$ \\ ${ }^{\text {a }}$ Director of the Active Travel Academy, School of Architecture and Cities. Westminster University, 35 Marylebone Road, London, UK \\ ${ }^{\mathrm{b}}$ Centre for Diet and Activity Research, MRC Epidemiology Unit, University of Cambridge, London, UK \\ ${ }^{\mathrm{c}}$ London School of Hygiene and Tropical Medicine, London, UK
}

\section{A R T I C L E I N F O}

\section{Keywords:}

Cycling

Walking

Infrastructure

Interventions

Evaluation

Physical activity

\begin{abstract}
A B S T R A C T
Introduction: This paper analyses three years' data from the People and Places longitudinal study. The study examines the travel behaviour impacts of major investments in active travel infrastructure in three Outer London boroughs (the 'mini- Hollands programme').

Methods: The People and Places survey, conducted annually in May-June, treats the mini-Holland interventions as a 'natural experiment'. Participants in other Outer London boroughs form a control group. The survey had over 3,000 respondents at baseline (May-June 2016). Three followup waves each had over 1400 repeat respondents. A difference-in-differences analysis was used to compare changes in active travel uptake in intervention and control groups. Further analysis examines likelihood of meeting targets for past-week active travel and all physical activity. Finally, the article conducts a health economic benefit assessment based on uptake of active travel at Wave 3.

Results: At all waves, living close to mini-Holland interventions ('high-dose' areas) was consistently associated with increased duration of past-week active travel, compared with the control group (44.0 extra minutes in Wave 2, 41.0 in Wave 1, and 41.5 in Wave 3). Changes in active travel behaviour were stronger in the high-dose area than in the low-dose area. Most of the increase was in walking. People living in high-dose areas were $13 \%$ more likely at Wave 3 to achieve 140 minutes active travel than people in control areas. People living in high- or low-dose areas in mini-Holland boroughs were more likely to be physically active for 5 days in the past week. The 20- year health economic benefit in high-dose areas from three years' of interventions (costing $£ 80$ million) is $£ 724$ million.

Conclusion: Ambitious interventions can yield substantial health economic benefits from changes in active travel. This includes early uptake of walking as well as cycling. Most of the increase was in walking but the ratio varied by year.
\end{abstract}

\section{Introduction}

Wider awareness of the health impacts of transport has encouraged policy-makers to take greater interest in walking and cycling (Fairnie et al., 2016). Studies show people express preferences for built environment improvements such as wide footways, protected cycle infrastructure, etc., and say such changes would encourage them to walk or cycle more (Blečić et al., 2016; Aldred et al., 2017).

\footnotetext{
* Corresponding author.

E-mail address: r.aldred@westminster.ac.uk (R. Aldred).
} 
Cross-sectional analysis suggests better infrastructure and destination proximity are associated with more active travel (Fraser et al., 2011; McCormack and Shiell, 2011; Kaczynski and Henderson, 2007).

While valuable, preference and cross-sectional evidence does not tell us whether infrastructural change leads to change in travel behaviour. Such evidence is crucial given the intense controversy often associated with such interventions (Castillo-Manzano and Sánchez-Braza, 2013; Aldred, 2019). Unfortunately, transport monitoring and evaluation has traditionally focused on estimating or measuring impacts on car users, usually time savings (Beukers et al., 2012).

Medically derived evidence hierarchies see the randomised controlled trial (RCT) as the gold standard. While well suited to pharmaceutical interventions, such trials work less well for built environment interventions where the researcher cannot usually control allocation to intervention and control groups. Natural experiment methods are one alternative approach to RCTs (Yang et al., 2010), (Sun et al., 2014). By treating an intervention as an experiment to be evaluated using a control (unexposed) and intervention (exposed) group, these studies can help us to distinguish between impacts of a specific intervention and potential confounders (e.g. wider secular trends towards increased active travel). The evidence base of natural experiments for active travel interventions (Kärmeniemi et al., 2018; Smith et al., 2017) has been growing but remains small. In general, studies have found that introducing active travel infrastructure is associated with growth in active travel, although not all find such associations; and more and better studies are still needed, particularly for walking infrastructure (Stappers et al., 2018).

This paper reports on three years' results from the third year of a longitudinal study into interventions in Outer London, UK (the 'mini-Hollands' programme). The study provides an opportunity to examine the longevity of initial changes, building on published first-year findings (Aldred et al., 2019) and qualitative analysis of perceptions using survey comments (Aldred, 2019). After reporting on three years' findings, the article conducts a health economic assessment of the estimated impacts of changes in physical activity and workplace absenteeism due to the programme. This is presented as health benefits and a monetised appraisal figure for comparison with the programme's cost.

\subsection{Study sites}

London's population is 8.7 million, projected to increase to 10.5 million by 2041. It is divided into 33 districts: 20 Outer and 13 Inner. While active and sustainable travel are high in the UK context, this varies across the capital. Outer London is more suburban than Inner London, with higher car use and less active travel (Fig. 1). Between 2005/06 and 2018/9, walking rose from 34\% to 38\% of trips in Inner London but fell from $29 \%$ to $26 \%$ in Outer London, while cycling rose from $2.5 \%$ to $4.4 \%$ in Inner London but remained stable at $1 \%$ in Outer London. ${ }^{1}$ While Outer London has more than $50 \%$ of trips made by sustainable (non-car) modes, its car mode share is more than double that of Inner London, and Transport for London's 2041 target for car mode share is 20\% across London (i.e. current Inner London levels).

While Transport for London (TfL) is the municipal transport authority, day-to-day control of 95\% of streets lies with the districts (all but one called 'boroughs'). Three Outer boroughs (Enfield, Kingston, Waltham Forest) were the successful bidders to TfL’s $£ 100$ million 'mini-Holland' programme. Initially focused on cycling, the programme incorporates interventions seeking to increase walking and improve public realm. Enfield and Waltham Forest are neighbouring boroughs in northeast London, while Kingston is in the southwest.

TfL confirm that by May/June 2019, just over $£ 80$ million had been spent across the three boroughs, with similar amounts of annual spending in financial years 2016/7, 2017/8, and 2018/9 (roughly representing in the study the periods between baseline and Wave 1, Wave 1-2, and Waves 2-3). For more on the programme, see TfL's Travel in London 11, page $100^{2}$. In brief: 102 separate schemes were proposed; 97 infrastructure schemes and 5 'supporting measures', due all to be complete by 2021-2. Infrastructure changes include area-based measures (known as 'modal filtering') to substantially reduce and calm motor traffic in neighbourhoods; and physically protected cycle lanes along main roads. The programme advanced fastest in Waltham Forest, with many neighbourhood-level interventions implemented early in the study period.

Fig. 2, Fig. 3, Fig. 4 and Fig. 5 provide the reader with a sense of the schemes' nature and scope. Fig. 2 shows a typical neighbourhood scheme in Waltham Forest with substantial restriction of through motor traffic, along with greening and other streetscape improvements. Figs. 3 and 4 respectively show a 'modal filter' in Walthamstow and a flagship new active travel route along a main road. Finally, Fig. 5 shows an image used to explain the plans in Enfield. These were less reliant on 'modal filtering' and neighbourhood-level interventions, and more focused on cycle routes.

\section{Methods}

A longitudinal survey design (involving a panel participating each year of the study) was used to examine whether and how miniHolland interventions are associated with changes in travel behaviour and attitudes. The key research question investigates whether residential proximity to interventions is associated with change in levels of active travel. This paper focuses on three-year outcomes, the programme's impacts on physical activity, and health and health economic benefits (see (Aldred, 2019; Aldred et al., 2019) for earlier work incorporating attitudinal analysis).

The previously published one-year results (Aldred et al., 2019) found that mini-Holland status (particularly being in the high-dose area) was associated with increased use of active travel at Wave 1, including an increased likelihood of any participation in past-week

\footnotetext{
${ }^{1}$ Source: TfL data, https://tfl.gov.uk/corporate/publications-and-reports/travel-in-london-reports.

2 http://content.tfl.gov.uk/travel-in-london-report-11.pdf.
} 


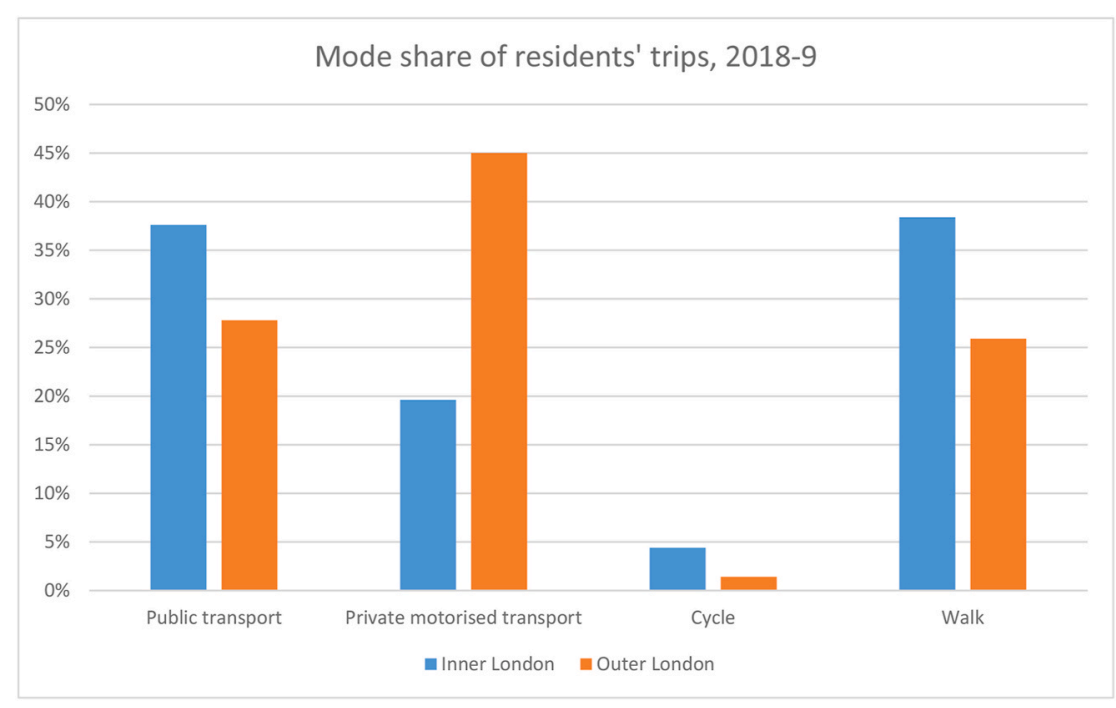

Fig. 1. Mode share of trips, Inner and Outer London, 2018-9 (source: Transport for London).

cycling. Mini-Holland status (again particularly being in the high-dose area) was also associated with increasingly positive perception of the local cycling environment, and therefore more positive overall perception of the local environment. Finally, mini-Holland status was associated with increased likelihood of saying that too much money is being spent on cycling, and decreased likelihood of saying too little is spent.

\subsection{Defining control and intervention groups}

Intervention group status is defined in three ways. Firstly, a simple comparison between mini-Holland boroughs and non-miniHolland boroughs in Outer London. However, planned interventions do not cover entire boroughs (Waltham Forest planned relatively little in the borough's North), and implementation was staged and sometimes slow.

Therefore, a second comparison uses 'high-dose' and 'low-dose' areas (see Fig. 6), based on annually elicited local stakeholder (borough officer) information about intervention areas. This information was requested in October/November, in relation to interventions that would be in place by May/June of the following year. In Wave 1 the stakeholder-defined high-dose areas covered $71 \%$ of participants in Waltham Forest, 24\% in Kingston and 5\% in Enfield. In Wave 2 these covered 72\% of participants in Waltham Forest, ${ }^{3} 35 \%$ in Kingston and 8\% in Enfield. In Wave 3 these covered 71\% of participants in Waltham Forest, 39\% in Kingston and 26\% in Enfield.

In Waves 2 and 3, with more route-based infrastructure completed, a third subdivision involved proximity to routes (Fig. 6). It used QGIS to calculate the most direct route from each participant's home location to any part of a new route, via TfL's Cynemon network of all legally cycleable routes. The proportion of participants living within $2 \mathrm{~km}$ of a new route increased between Waves 2 and 3 in MiniHolland boroughs such that in Wave 3 this covered a sizeable majority of participants in all three boroughs versus $2 \%$ in non-miniHolland boroughs. The 'high-dose' areas were unsurprisingly correlated with a higher proportion of people living closer to a route than were the 'low-dose' areas, with nearly all living within $2 \mathrm{~km}$ of a route both in W2 and W3 (Fig. 7).

\subsection{Sampling and the questionnaire}

Eligible respondents were Outer London residents aged 16+. The survey was described as exploring travel behaviour and attitudes to local places in Outer London. It did not mention 'mini-Hollands' to avoid biasing responses owing to the programme's controversial nature. (see Aldred 2019). Initially random household sampling was used, with postcards sent containing a survey URL to addresses within Lower Level Super Output Areas cluster sampled across Outer London, with the same number of clusters sampled in mini-Holland and non mini-Holland boroughs. However, the response rate was $\sim 1 \%$, so TfL then contacted on our behalf people from two customer databases (Oyster - public transport - and Cyclist) who had agreed to re-contact. As with the postal sampling the same number of requests to participate were sent to those recorded as living in mini-Holland as in non mini-Holland boroughs. Emails to 106,671 people yielded a response rate of $\sim 2 \%$.

Comparison of participant demographics and travel behaviour with a representative local sample are provided in Figs. 9 and 10.

\footnotetext{
${ }^{3}$ This variation in Waltham Forest from $71 \%$ to $72 \%$ across Waves 1-3 reflects differences in the follow-up sample, rather than any differences in the underlying high-dose area. Likewise the variation in Kingston between 35\% and 39\% across Waves 2-3 reflects differences in the follow-up sample, rather than any differences in the underlying high-dose area.
} 


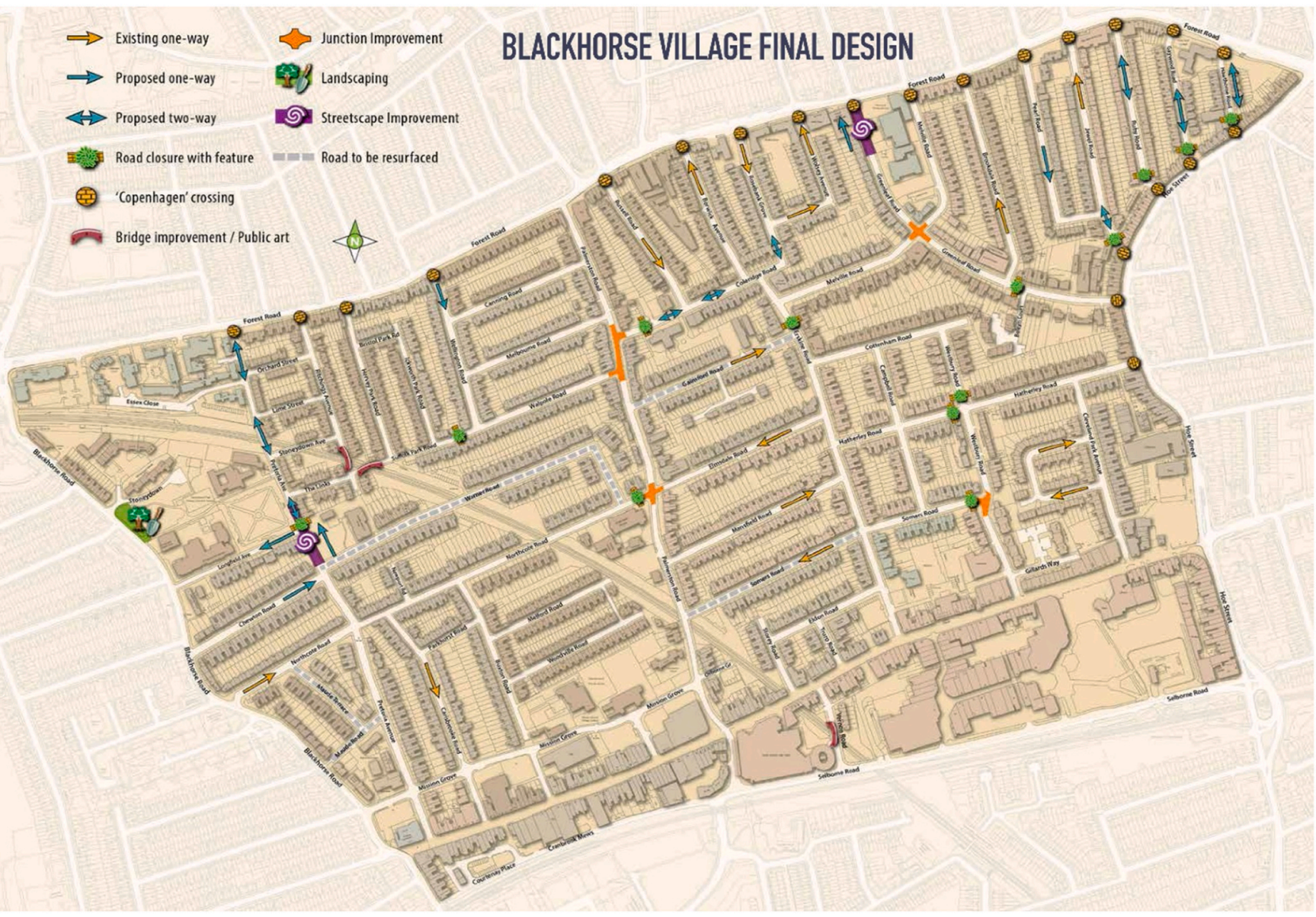

Fig. 2. 'Blackhorse Village' design for modal filters and other streetscape interventions (source: We support Waltham Forest Mini-Holland). 


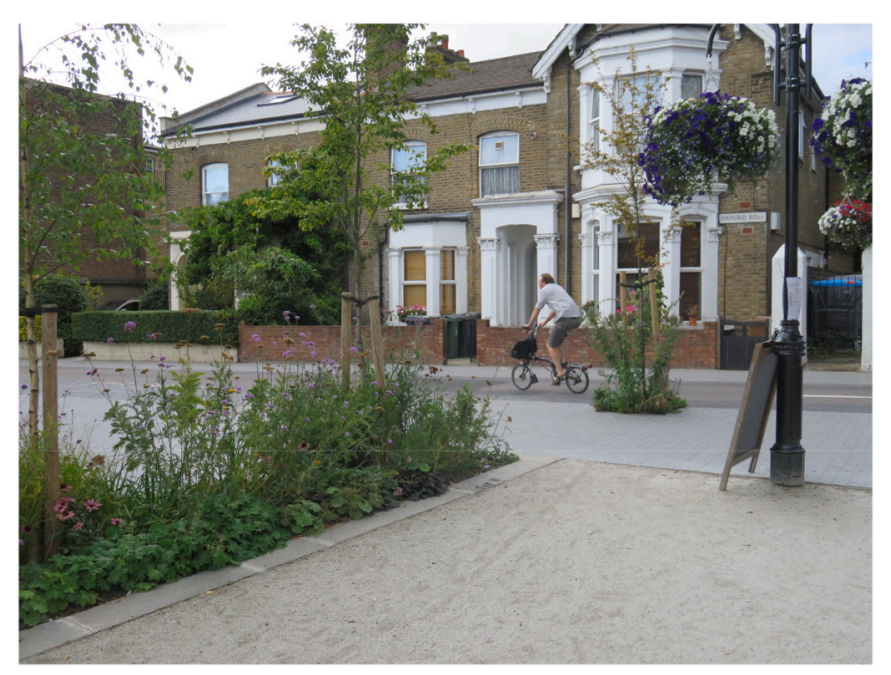

Fig. 3. Example of a modal filter, Walthamstow neighbourhood (source: Rachel Aldred).

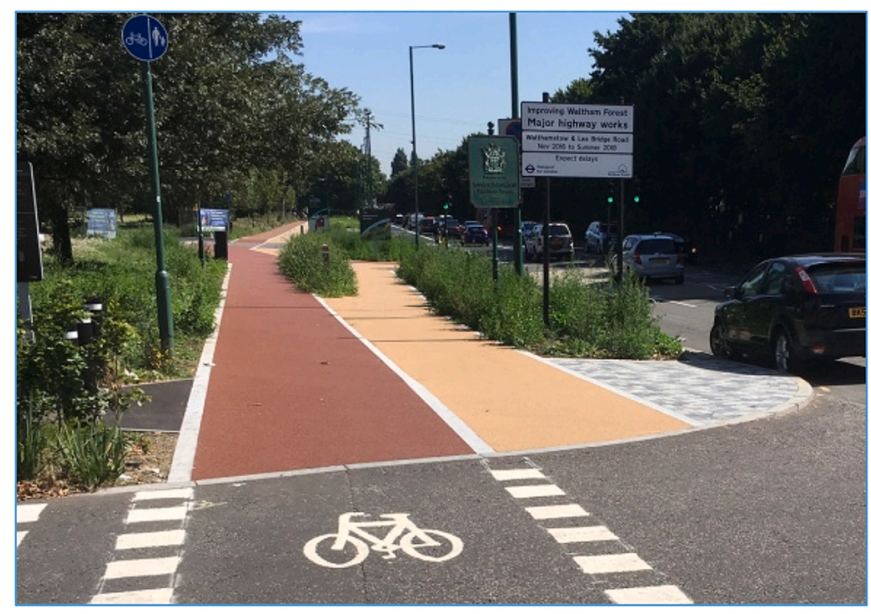

Fig. 4. Example of a new active travel route along a main road, Waltham Forest (source: Joseph Croft).

These show (i) under-representation of young and Black and minority ethnic people, those in paid work, and non-car owners, (ii) some over-representation of cyclists (who remained a minority, e.g. 16-18\% having cycled in the past week, against a population comparator of 8-9\%), and (iii) similarity in both biases for intervention and control groups. These biases may over-represent the likelihood of change, given that around a third of our overall sample came from TfL's Cyclist database and hence - even if they did not currently cycle - might be more receptive to cycling interventions. Conversely, other biases, particularly the under-representation of young people and those living without a car, and the over-representation of retired people are likely to pull in the opposite direction (given the likely demographic near-markets for cycling).

The survey was administered using Qualtrics software: https://www.qualtrics.com/uk/. A phone option was provided at baseline but few used it and all agreed to use the online questionnaire in future waves. Informed consent was gathered via a participant information sheet forming part of the survey instrument. The survey was open at similar times each wave (early May to mid June).Fig. 8 shows the composition of the sample at Baseline, Wave 1, and Wave 3, with follow-up rates similar across the control group and the three mini-Holland boroughs.

Participants were asked about demographic and social-economic information, with questions on travel behaviour that included a past-week travel diary on daily use of different modes, including for walking, cycling, and car use, how many minutes. This is selfreport data and hence there may be recall or social desirability bias, as with other travel surveys routinely used in transport research and planning. Because Transport for London was interested in amounts of active travel for any purpose, we did not collect trip-level data (which would have required a 'journey purpose') but rather data on time spent travelling, which has advantages and disadvantages in assessing behaviour change (e.g. a new cut-through could make cycling or walking quicker, leading to a measured reduction in active travel minutes). They were asked on how many days within the past week they had done at least 30 minutes of 


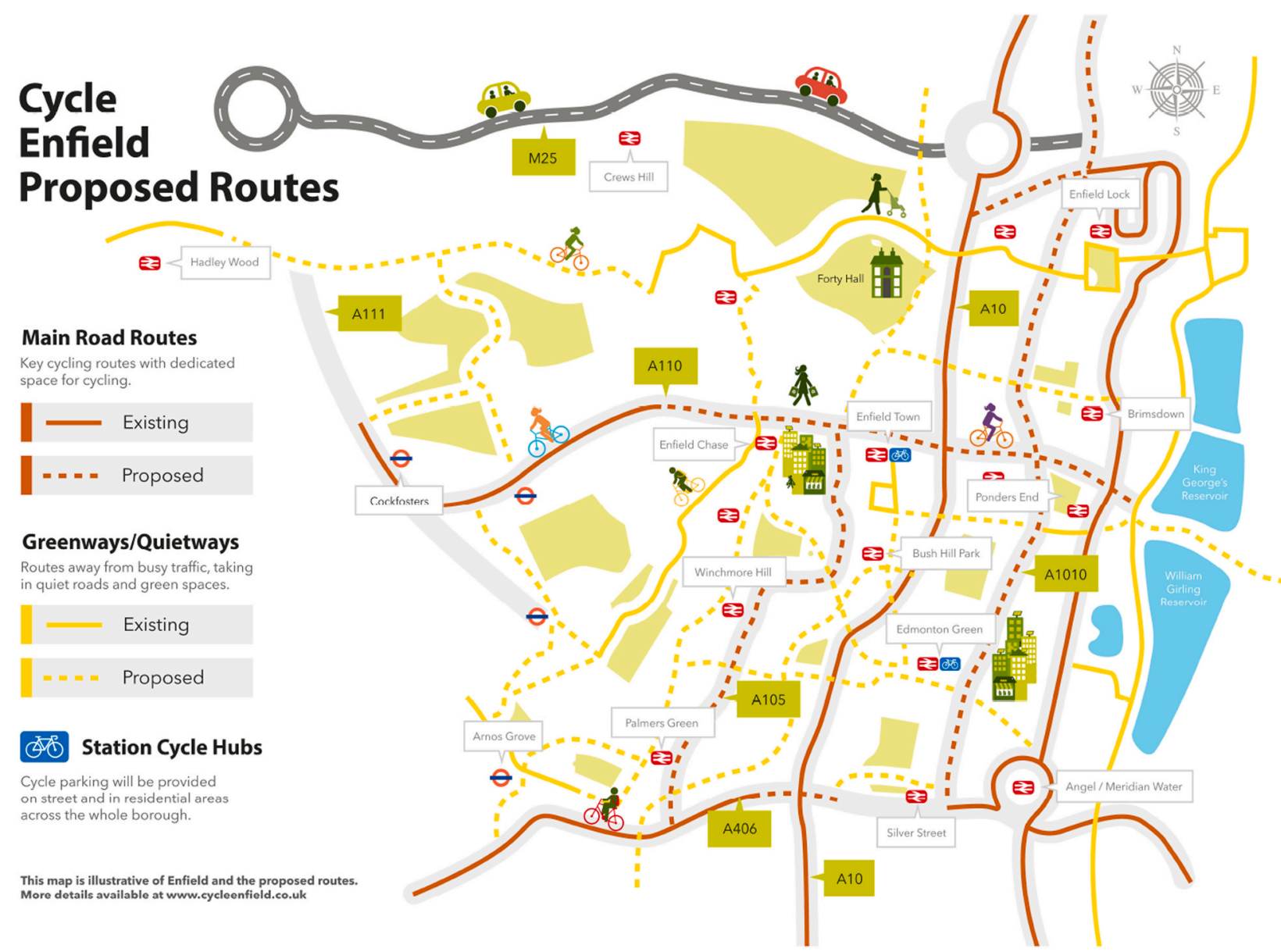

Fig. 5. Map of proposed Enfield Routes (source: Cycle Enfield).

moderate to vigorous physical activity (including through travel).

\subsection{Analysis}

We constructed survey weights to allow for differences in sample composition between the three survey sources (specifically, whether the participant responded to a leaflet, or came from one of the TfL databases), and updated these annually based on follow-up rates (see Appendix 1). All regression analyses adjust for the corresponding measure at baseline, e.g. when the outcome is whether the participant did any past-week cycling at Wave 3, the regression model is adjusted for whether that participant did any past-week cycling at baseline.

In analysing change in travel behaviour, we entered continuous baseline measures of past-week travel as linear terms, alongside quadratic terms if these were statistically significant. We included these quadratic terms to improve model fit, and therefore increase precision; our study findings are similar in analyses excluding these quadratic terms. After conducting minimally-adjusted analyses, we adjusted for other demographic and socio-economic characteristics, presented here. Specifically: gender (male/female), age (years), ethnicity (white/black or minority ethnic), disability status (Yes/No), household type, employment status, and presence of household cars or vans. We used Poisson regression with robust standard errors for binary outcomes because many of our binary outcomes are common (Zou, 2004).

For our analysis of monetised benefits due to increased physical activity, we used the DfT's TAG Active Mode Appraisal spreadsheet approach. ${ }^{4}$ In part developed by JW, AG, and others, this approach extends transport appraisal's traditional focus on car journey times to incorporate monetised benefits from impacts of increasing active travel. We calculated benefits both from reductions in premature mortality and in sickness absence. In brief the approach uses dose response relationships between physical activity energy expenditure from walking or cycling (we combined both together) and risk of premature death and numbers of days of sickness absence. Physical

\footnotetext{
${ }^{4}$ https://www.gov.uk/government/publications/tag-unit-a5-1-active-mode-appraisal. As well as the benefits analysed here, TAG can also be used to calculate impacts related to congestion reduction, carbon savings, journey experience, and air pollution.
} 


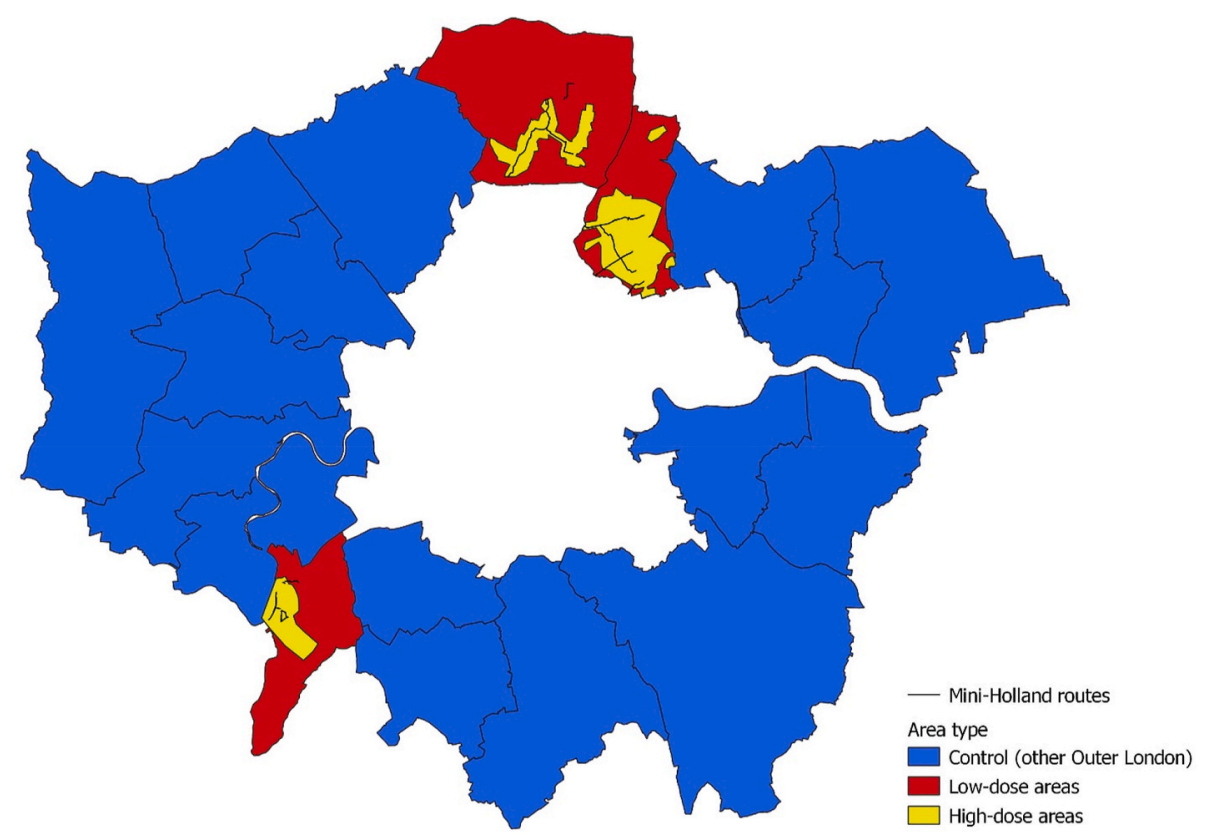

Fig. 6. Location of high-dose areas and routes in the three boroughs that were complete by mid-2019 (Wave 3).

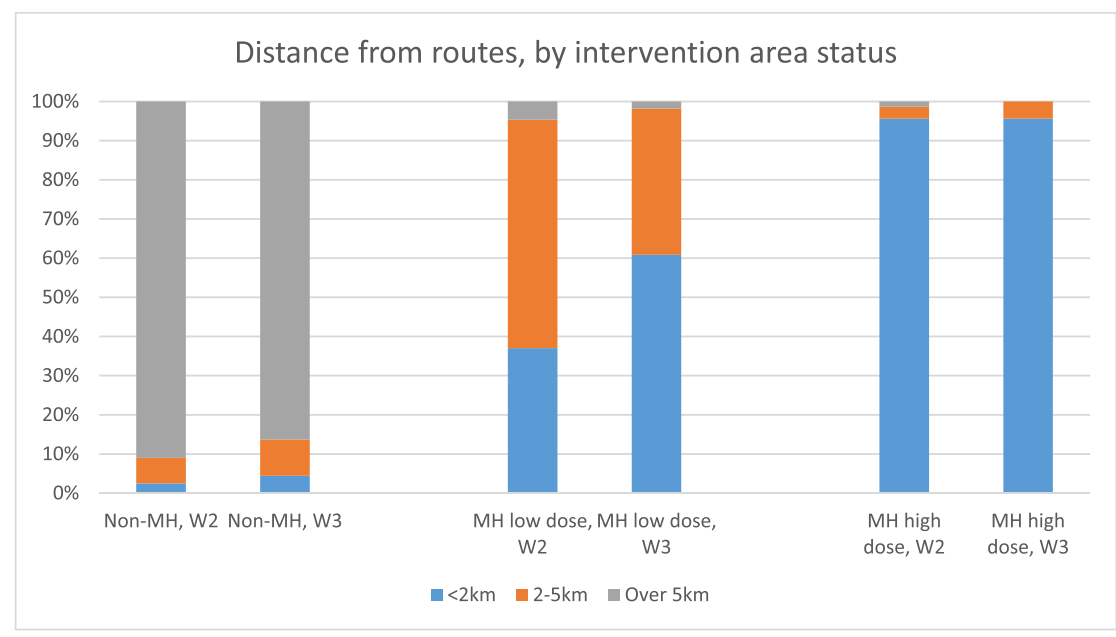

Fig. 7. Distance of participants from a new cycle route in Wave 2 and Wave 3.

activity energy expenditure was calculated as MET (Metabolically Equivalent Task hours per week). Premature deaths averted are converted into years of life lost averted using Global Burden of Disease age and gender specific relationships.

In calculating the population affected by the interventions, we used data from the Office for National Statistics ${ }^{5}$ to estimate the adult population aged 20-80 in mid-2016 (i) living in the high-dose areas and (ii) living in Outer London. This provided estimates of adults exposed to the intervention at Wave $3(228,807)$ and who would be exposed if the programme were rolled-out across the whole of Outer London $(3,688,316)$, the latter as a possible future scenario. For sensitivity analysis we created estimates of increased active travel among those aged 20-49, 50-64, and 65-79, to match age groups used in TAG. We did not use these as our main analysis as there were small numbers and very high uncertainty in the point estimates once subdivided by both age and sex, but when aggregated the overall health impacts were similar and somewhat higher. We assumed no benefit in the over 80s. For calculating sickness absence we only included impacts in the age group 20 to 64, using gender, age, and region specific rates. Uptake was assumed to be immediate, as

\footnotetext{
5 https://www.ons.gov.uk/peoplepopulationandcommunity/populationandmigration/populationestimates/datasets/ lowersuperoutputareamidyearpopulationestimates.
} 


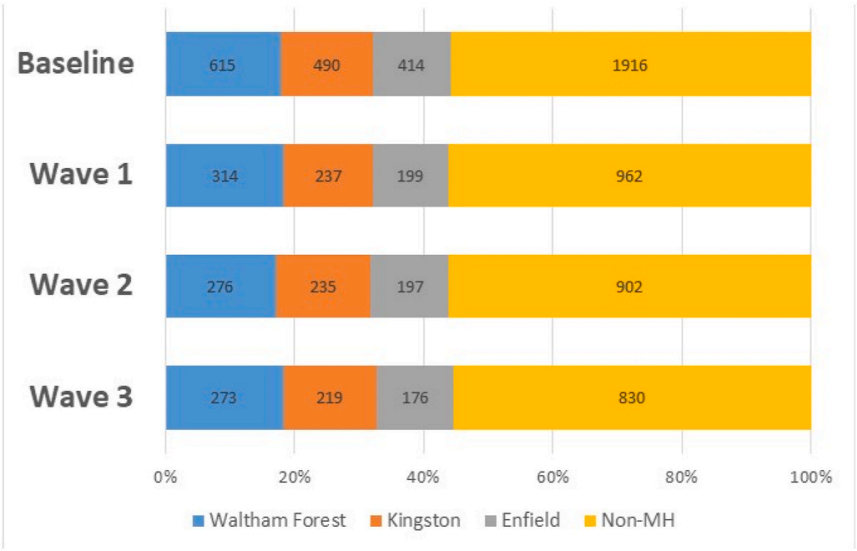

Fig. 8. Number of participants from mini-Holland and non-mini-Holland boroughs, at Baseline, Wave 1, Wave 2 and Wave 3.

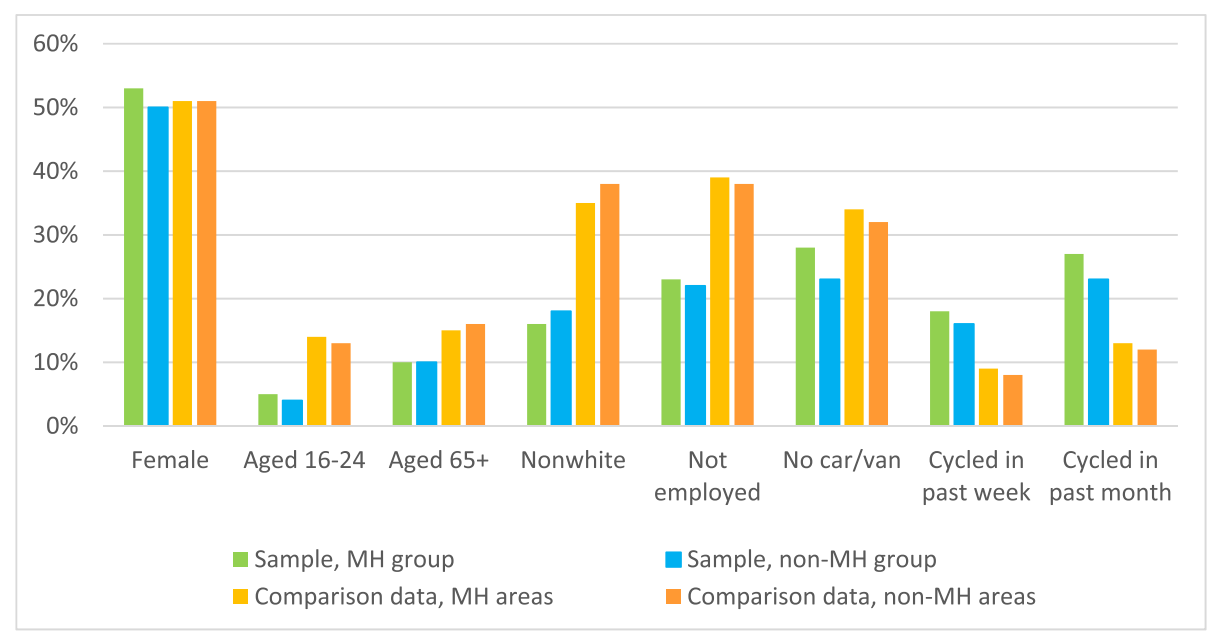

Fig. 9. Comparing the baseline sample $(\mathrm{N}=3435)$ with other data.

Sources for comparison data: ONS midyear population data mid-2015, for age and sex. Census 2011 for ethnicity, employment status and car ownership. Active People Survey 2014/15 for cycling and walking.

we saw broadly similar higher rates of walking and cycling related physical activity at years 1,2 , and 3 . The infrastructure was assumed to last for 20 years from 2017 . We used a discount rate of $1.5 \%$.

The calculation is available in a spreadsheet (Appendix 2) for download.

\section{Results}

This section discusses (i) changes in the amount of walking and cycling, and past-week participation in walking and cycling, (ii) changes in the proportion of being meeting active travel and physical activity targets, and (iii) the health economic impact of changes in active travel due to the mini-Holland interventions.

\subsection{Past-week cycling}

Past-week cycling was generally strongest in 'high-dose' areas or close to new routes (Table 1, showing regression coeficcients associated with intervention groups for each wave, for cycling participation and amounts). Comparing the mini-Holland to the nonmini-Holland control group, there were only borderline significant trends towards increased participation in cycling, and this only at Waves 1 and 3. By contrast, the point estimate for increased participation in cycling was higher in the high-dose areas and reached statistical significance in Waves 1 and 3 (Wave 3: $1.35, \mathrm{p}=0.005$ ) and areas nearest new routes (Wave 3: $1.30, \mathrm{p}=0.03$ ). For pastweek minutes of cycling, the pattern of results was the same as for any past-week cycling. At Wave 3 effects reached statistical significance when comparing the high-dose mini-Holland areas to the control group (point estimate of 13 extra minutes/week, $\mathrm{p}=0.03$ ) 


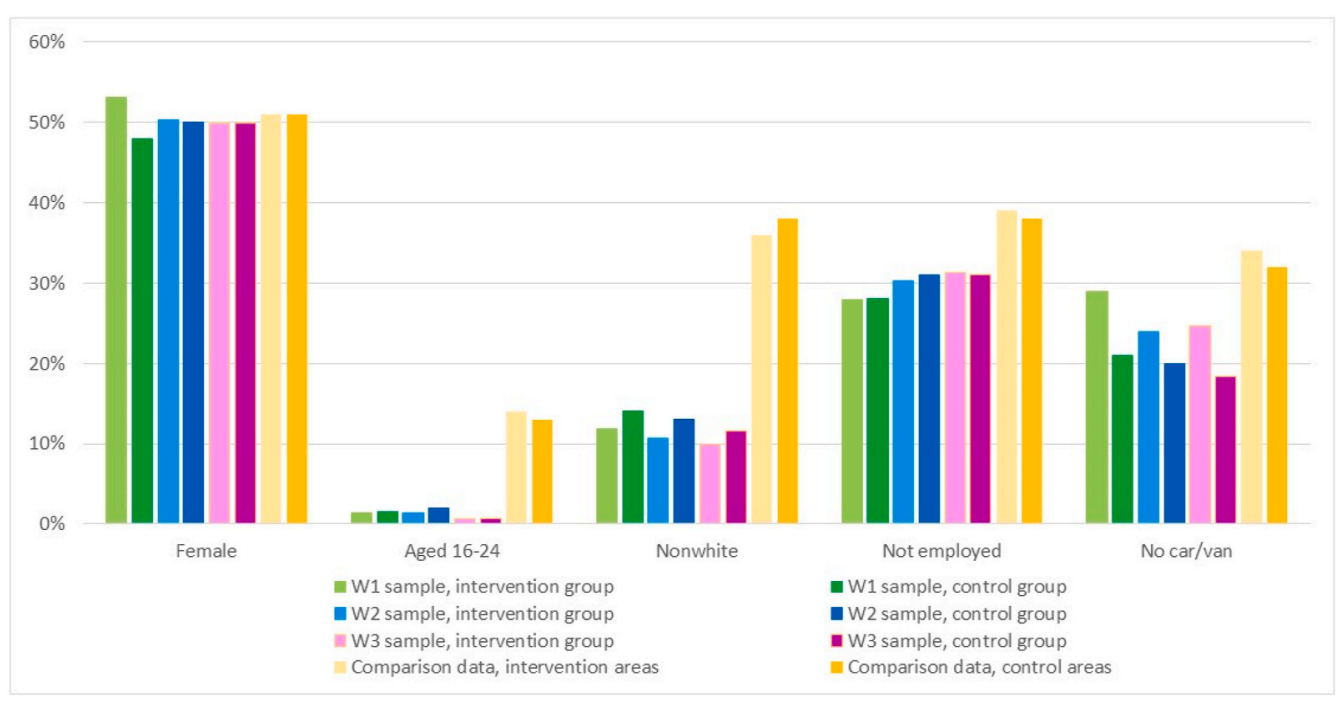

Fig. 10. Comparing the Wave $1(\mathrm{~N}=1712)$, Wave $2(\mathrm{~N}=1610)$ and Wave $3(\mathrm{~N}=1498)$ samples with other data.

Sources for comparison data: ONS midyear population data mid-2015, for age and gender. Census 2011 for ethnicity, employment status and car ownership.

Table 1

Predictors of past-week cycling at Wave 1, 2 and 3: rate ratios (95\% CI).

\begin{tabular}{|c|c|c|c|c|c|c|}
\hline & \multicolumn{3}{|c|}{$\begin{array}{l}\% \text { doing any cycling in the past week: rate ratios }(95 \% \\
\mathrm{CI})\end{array}$} & \multicolumn{3}{|c|}{$\begin{array}{l}\text { Change in minutes of past-week cycling, compared to control group } \\
(95 \% \mathrm{CI})\end{array}$} \\
\hline & Wave 1 & Wave 2 & Wave 3 & Wave 1 & Wave 2 & Wave 3 \\
\hline & $(\mathrm{N}=1712)$ & $(\mathrm{N}=1610)$ & $(\mathrm{N}=1498)$ & $(\mathrm{N}=1634)$ & $(\mathrm{N}=1444)$ & $(\mathrm{N}=1498)$ \\
\hline Non-mini-Holland & 1 & 1 & 1 & 0 & 0 & 0 \\
\hline Mini-Holland & $\begin{array}{l}1.16 \\
(0.99,1.36) \dagger\end{array}$ & $\begin{array}{l}1.04 \\
(0.87,1.24)\end{array}$ & $\begin{array}{l}1.18 \\
(0.98,1.42) \dagger\end{array}$ & $\begin{array}{l}4.1 \\
(-4.0,12.2)\end{array}$ & $\begin{array}{l}-2.0 \\
(-9.8,5.8)\end{array}$ & $\begin{array}{l}5.4 \\
(-3.2,14.0)\end{array}$ \\
\hline Non-mini-Holland & 1 & 1 & 1 & 0 & 0 & 0 \\
\hline Low-dose Mini-Holland & $\begin{array}{l}1.10 \\
(0.90,1.34)\end{array}$ & $\begin{array}{l}0.98 \\
(0.79,1.22)\end{array}$ & $\begin{array}{l}1.00 \\
(0.78,1.28)\end{array}$ & $\begin{array}{l}1.4 \\
(-8.5,11.2)\end{array}$ & $\begin{array}{l}-1.7 \\
(-11.2,7.8)\end{array}$ & $\begin{array}{l}-1.5 \\
(-10.8,7.9)\end{array}$ \\
\hline High-dose Mini-Holland & $\begin{array}{l}1.24 \\
(1.02,1.52)^{*}\end{array}$ & $\begin{array}{l}1.11 \\
(0.88,1.40)\end{array}$ & $\begin{array}{l}1.35 \\
(1.09,1.67)^{* *}\end{array}$ & $\begin{array}{l}8.9 \\
(-3.1,20.8)\end{array}$ & $\begin{array}{l}-2.4 \\
(-13.0,8.2)\end{array}$ & $\begin{array}{l}13.3 \\
(1.0,25.6)^{*}\end{array}$ \\
\hline$\geq 5 \mathrm{~km}$ from $\mathrm{MH}$ routes & & 1 & 1 & & 0 & 0 \\
\hline $2-4.9 \mathrm{~km}$ from $\mathrm{MH}$ routes & & $\begin{array}{l}1.07 \\
(0.85,1.34)\end{array}$ & $\begin{array}{l}0.91 \\
(0.66,1.25)\end{array}$ & & $\begin{array}{l}2.7 \\
(-6.2,11.6)\end{array}$ & $\begin{array}{l}-2.8 \\
(-12.7,7.2)\end{array}$ \\
\hline$<2 \mathrm{~km}$ from $\mathrm{MH}$ routes & & $\begin{array}{l}1.16 \\
(0.95,1.43)\end{array}$ & $\begin{array}{l}1.30 \\
(1.06,1.61)^{*}\end{array}$ & & $\begin{array}{l}3.7 \\
(-7.1,14.5)\end{array}$ & $\begin{array}{l}10.6 \\
(0.7,20.4)^{*}\end{array}$ \\
\hline
\end{tabular}

$\mathrm{tp}<0.10,{ }^{*} \mathrm{p}<0.05,{ }^{* *} \mathrm{p}<0.01,{ }^{* * *} \mathrm{p}<0.001$, for difference from the non-mini-Holland group. All analyses adjust for the Baseline measure of the outcome in question, plus gender, age, ethnicity, disability, household type, employment type and number of cars in the household.

and comparing the areas nearest the new routes to the control group (11 extra minutes, $\mathrm{p}=0.04$ ).

Tables containing levels of walking and cycling alongside the regression coefficients for all three follow-up survey waves, and summary information related to the baseline Wave 1 sample, are included in Appendix 1 (Tables A2-A8).

\subsection{Past-week walking and active travel}

Table 2 and Table 3 present evidence about changes in walking and all active travel. There was generally little or no evidence of differences by mini-Holland status in the proportion of individuals doing any past-week walking or active travel. At baseline, these behaviours were already very common ( $88 \%$ for walking, $90 \%$ for active travel), the sample similar in this regard to the local population. See Tables A9-A11 (Appendix 1) to see rates of active travel, including levels of participants achieving the 140-min target.

There was evidence across all Waves that duration of past-week walking and active travel was higher in the mini-Holland group than the non-mini-Holland group. This trend was consistently observed, although not statistically significant in Wave 3 . The clearest evidence of differences in past-week walking/active travel time was seen when comparing high-dose and control areas. In the miniHolland high-dose group, there was evidence of increased walking duration in Waves 1 and 2 ( $\mathrm{p}=0.05$ in Wave $1 ; \mathrm{p}=0.004$ in Wave 2 ), and increased active travel duration in all three Waves ( $p=0.02$ in Wave $1 ; p=0.02$ in Wave 2; $p=0.03$ in Wave 3 ). 
Table 2

Predictors of past-week walking at Wave 1, 2 and 3: rate ratios (95\% CI). See notes to Table 1.

\begin{tabular}{|c|c|c|c|c|c|c|}
\hline & \multicolumn{3}{|c|}{$\%$ doing any walking in the past week: rate ratios $(95 \% \mathrm{CI})$} & \multicolumn{3}{|c|}{$\begin{array}{l}\text { Minutes of walking in the past week: regression coefficient }(95 \% \\
\mathrm{CI})\end{array}$} \\
\hline & $\begin{array}{l}\text { Wave } 1(\mathrm{~N}= \\
1712)\end{array}$ & $\begin{array}{l}\text { Wave } 2(\mathrm{~N}= \\
1610)\end{array}$ & $\begin{array}{l}\text { Wave } 3(\mathrm{~N}= \\
1498)\end{array}$ & $\begin{array}{l}\text { Wave } 1(\mathrm{~N}= \\
1634)\end{array}$ & $\begin{array}{l}\text { Wave } 2(\mathrm{~N}= \\
1444)\end{array}$ & $\begin{array}{l}\text { Wave } 3(\mathrm{~N}= \\
1498)\end{array}$ \\
\hline Non-mini-Holland & 1 & 1 & 1 & 0 & 0 & 0 \\
\hline Mini-Holland & $1.03(0.98,1.07)$ & $1.02(0.98,1.06)$ & $1.02(0.98,1.06)$ & $19.0(-1.8,39.8) \dagger$ & $26.3(4.8,47.9)^{*}$ & $13.6(-13.1,40.3)$ \\
\hline Non-mini-Holland & 1 & 1 & 1 & 0 & 0 & 0 \\
\hline Low-dose Mini-Holland & $1.03(0.98,1.08)$ & $1.01(0.96,1.06)$ & $1.00(0.95,1.06)$ & $11.4(-11.5,34.4)$ & $13.1(-11.8,38.0)$ & $0.8(-30.3,32.0)$ \\
\hline High-dose Mini-Holland & $1.02(0.97,1.08)$ & $1.03(0.98,1.08)$ & $1.04(0.99,1.09) \dagger$ & $32.0(-0.1,64.1) \dagger$ & $\begin{array}{l}45.7(14.3 \\
77.1)^{* *}\end{array}$ & $28.5(-8.0,65.1)$ \\
\hline$\geq 5 \mathrm{~km}$ from $\mathrm{MH}$ routes & & 1 & 1 & & 0 & 0 \\
\hline $\begin{array}{l}2-4.9 \mathrm{~km} \text { from } \mathrm{MH} \\
\quad \text { routes }\end{array}$ & & $1.01(0.95,1.06)$ & $1.01(0.94,1.07)$ & & $21.8(-5.0,48.5)$ & $\begin{array}{l}-14.2(-46.6 \\
18.3)\end{array}$ \\
\hline$<2 \mathrm{~km}$ from $\mathrm{MH}$ routes & & $1.06(1.01,1.11)$ & $1.02(0.98,1.07)$ & & $30.9(3.8,58.0)^{*}$ & $21.6(-9.1,52.3)$ \\
\hline
\end{tabular}

Table 3

Predictors of past-week active travel at Wave 1, 2 and 3: adjusted rate ratios and regression coefficients (95\% CI). See notes to Table 1.

\begin{tabular}{|c|c|c|c|c|c|c|c|c|c|}
\hline & \multicolumn{3}{|c|}{$\begin{array}{l}\% \text { doing any active travel in the past week: } \\
\text { rate ratios }(95 \% \mathrm{CI})\end{array}$} & \multicolumn{3}{|c|}{$\begin{array}{l}\% \text { doing } 140+\text { minutes active travel in the } \\
\text { past week: rate ratios }(95 \% \mathrm{CI})\end{array}$} & \multicolumn{3}{|c|}{$\begin{array}{l}\text { Minutes of active travel in the past week: } \\
\text { regression coefficient }(95 \% \mathrm{CI})\end{array}$} \\
\hline & $\begin{array}{l}\text { Wave } 1(\mathrm{~N} \\
=1712)\end{array}$ & $\begin{array}{l}\text { Wave } 2(\mathrm{~N} \\
=1610)\end{array}$ & $\begin{array}{l}\text { Wave } 3(\mathrm{~N} \\
=1498)\end{array}$ & $\begin{array}{l}\text { Wave } 1(\mathrm{~N} \\
=1634)\end{array}$ & $\begin{array}{l}\text { Wave } 2(\mathrm{~N} \\
=1444)\end{array}$ & $\begin{array}{l}\text { Wave } 3(\mathrm{~N} \\
=1498)\end{array}$ & $\begin{array}{l}\text { Wave } 1(\mathrm{~N} \\
=1634)\end{array}$ & $\begin{array}{l}\text { Wave } 2(\mathrm{~N} \\
=1444)\end{array}$ & $\begin{array}{l}\text { Wave } 3(\mathrm{~N} \\
=1498)\end{array}$ \\
\hline $\begin{array}{l}\text { Non-mini- } \\
\text { Holland }\end{array}$ & 1 & 1 & 1 & 1 & 1 & 1 & 0 & 0 & 0 \\
\hline Mini-Holland & $\begin{array}{l}1.03(0.99, \\
1.07)\end{array}$ & $\begin{array}{l}1.02(0.98, \\
1.05)\end{array}$ & $\begin{array}{l}1.01(0.98, \\
1.05)\end{array}$ & $\begin{array}{l}1.12(1.04 \\
1.21)^{* *}\end{array}$ & $\begin{array}{l}1.03(0.96 \\
1.10)\end{array}$ & $\begin{array}{l}1.10(1.02 \\
1.18)^{*}\end{array}$ & $\begin{array}{l}23.0(1.0 \\
44.9)^{*}\end{array}$ & $\begin{array}{l}23.8(0.9 \\
46.7)^{*}\end{array}$ & $\begin{array}{l}19.2(-8.5 \\
47.0)\end{array}$ \\
\hline $\begin{array}{l}\text { Non-mini- } \\
\text { Holland }\end{array}$ & 1 & 1 & 1 & 1 & 1 & 1 & 0 & 0 & 0 \\
\hline $\begin{array}{l}\text { Low-dose } \\
\text { Mini- } \\
\text { Holland }\end{array}$ & $\begin{array}{l}1.03(0.98 \\
1.07)\end{array}$ & $\begin{array}{l}1.00(0.96 \\
1.05)\end{array}$ & $\begin{array}{l}0.99(0.94 \\
1.04)\end{array}$ & $\begin{array}{l}1.11(1.02, \\
1.21)^{*}\end{array}$ & $\begin{array}{l}0.99(0.91, \\
1.08)\end{array}$ & $\begin{array}{l}1.07(0.97, \\
1.17)\end{array}$ & $\begin{array}{l}12.5(-12.1 \\
37.1)\end{array}$ & $\begin{array}{l}10.1(-16.1, \\
36.3)\end{array}$ & $\begin{array}{l}0.3(-31.8, \\
32.5)\end{array}$ \\
\hline $\begin{array}{l}\text { High-dose } \\
\text { Mini- } \\
\text { Holland }\end{array}$ & $\begin{array}{l}1.03(0.98, \\
1.08)\end{array}$ & $\begin{array}{l}1.03(0.99, \\
1.08)\end{array}$ & $\begin{array}{l}1.04(1.00, \\
1.09) \dagger\end{array}$ & $\begin{array}{l}1.14(1.04 \\
1.24)^{* *}\end{array}$ & $\begin{array}{l}1.08(0.99, \\
1.17)\end{array}$ & $\begin{array}{l}1.13(1.04 \\
1.23)^{* *}\end{array}$ & $\begin{array}{l}41.0(7.0 \\
75.0)^{*}\end{array}$ & $\begin{array}{l}44.0(10.5 \\
77.5)^{*}\end{array}$ & $\begin{array}{l}41.5(3.3 \\
79.7)^{*}\end{array}$ \\
\hline $\begin{array}{l}\geq 5 \mathrm{~km} \text { from } \\
\quad \mathrm{MH} \text { routes }\end{array}$ & & 1 & 1 & & 1 & 1 & & 0 & 0 \\
\hline $\begin{array}{r}2-4.9 \mathrm{~km} \text { from } \\
\text { MH routes }\end{array}$ & & $\begin{array}{l}1.02(0.97, \\
1.07)\end{array}$ & $\begin{array}{l}1.00(0.94, \\
1.06)\end{array}$ & & $\begin{array}{l}1.07(0.97, \\
1.17)\end{array}$ & $\begin{array}{l}1.09(0.98, \\
1.22)\end{array}$ & & $\begin{array}{l}24.4(-3.9, \\
52.6)\end{array}$ & $\begin{array}{l}-17.0 \\
(-50.3 \\
16.2)\end{array}$ \\
\hline $\begin{array}{l}<2 \mathrm{~km} \text { from } \\
\quad \mathrm{MH} \text { routes }\end{array}$ & & $\begin{array}{l}1.06(1.02, \\
1.10)^{* *}\end{array}$ & $\begin{array}{l}1.03(0.99, \\
1.07)\end{array}$ & & $\begin{array}{l}1.06(0.98, \\
1.15)\end{array}$ & $\begin{array}{l}1.10(1.02, \\
1.20)^{*}\end{array}$ & & $\begin{array}{l}35.7(6.6 \\
64.8) *\end{array}$ & $\begin{array}{l}33.0(0.9 \\
65.1)^{*}\end{array}$ \\
\hline
\end{tabular}

Table 4

Predictors of past-week physical activity at Waves 1, 2 and 3: rate ratios (95\% CI). See notes to Table 1.

\begin{tabular}{llll}
\hline & \% Doing $30+$ minutes PA on at least 5 days in the past week: rate ratios $(95 \% \mathrm{CI})$ \\
\cline { 2 - 4 } & Wave $1(\mathrm{~N}=1712)$ & Wave $2(\mathrm{~N}=1610)$ & Wave $3(\mathrm{~N}=1498)$ \\
\hline Non-mini-Holland & 1 & 1 & 1 \\
Mini-Holland & $1.16(1.01,1.33)^{*}$ & $1.14(0.99,1.30) \dagger$ & $1.18(1.03,1.36)^{*}$ \\
Non-mini-Holland & 1 & 1 & $1.20(1.00,1.42)^{*}$ \\
Low-dose Mini-Holland & $1.19(1.02,1.40)^{*}$ & $1.08(0.92,1.27)$ & $1.17(0.99,1.38) \dagger$ \\
High-dose Mini-Holland & $1.10(0.92,1.32)$ & $1.21(1.03,1.44)^{*}$ & 1 \\
$\geq 5$ km from MH routes & & $1.06(0.89,1.26)$ & $1.23(1.01,1.50)^{*}$ \\
$2-4.9$ km from MH routes & & $1.15(0.98,1.35) \dagger$ & $1.14(0.97,1.34)$ \\
\hline 2 km from MH routes & & &
\end{tabular}

In adjusted analyses, in Wave 1 the regression coefficient for past-week active travel minutes for the high-dose group, as compared to the non-mini-Holland group, was 41.0 extra minutes per participant per week in Wave 1 (95\% CI 7.0, 75.0, p = 0.02). The equivalent point estimate was 44 extra minutes in Wave $2(95 \% \mathrm{CI}+11$ to +78$)$, and 42 in Wave $3(95 \% \mathrm{CI}+3$ to +80$)$. There was evidence in Waves 2 and 3 that those living $<2 \mathrm{~km}$ from a mini-Holland route had higher past-week walking and active travel times than those living $\geq 5 \mathrm{~km}$ away. 
Finally, we examined what proportion of participants met Transport for London (TfL's) target of 140+ minutes of active travel per week. Overall, around two thirds met this target (62\% in Wave 1, 67\% in Wave 2 and 66\% in Wave 3). In Waves 1 and 3, there was evidence in adjusted analyses that participants in the mini-Holland group were more likely to achieve it. The strongest effects were in high-dose mini-Holland areas (point estimate 1.14, $\mathrm{p}=0.005$, in Wave 1; point estimate 1.13, $\mathrm{p}=0.004$, in Wave 3).

\subsection{Past-week physical activity}

We complemented our analyses of past-week cycling, walking and active travel with analysis that examined the probability of doing $30+$ minutes of physical activity on at least five days in the past week (Table 4). Overall around a third met this target (32\% in Wave 1, 33\% in Wave 2, 34\% in Wave 3), ${ }^{6}$ with low-to-moderate correlation with active travel outcomes. In all three Waves there was a trend towards higher proportion of participants meeting this threshold in the mini-Holland boroughs ( $\mathrm{p}=0.04$ in Wave $1 ; \mathrm{p}=0.07$ in Wave $2 ; \mathrm{p}=0.02$ in Wave 3 ). In contrast to the findings for active travel, the effect was not consistently greater in high-dose areas, nor areas closest to mini-Holland routes. See Tables A12-A14 (Appendix 1) to see rates of physical activity, including levels of participants achieving the target at the various waves.

\subsection{Health and health economic benefits}

For the main analysis, we assumed an extra $13.3 \mathrm{~min}$ of cycling per person exposed to the intervention, and an extra 28.5 min of walking. These came from the point estimates for the high-dose group at Wave 3 . We used $£ 60,000$ as the value of a statistical life year at 2012 prices, a discount rate of 1.5\%, and a twenty-year appraisal period running from 2017 to 2037 . For the Wave 3 high-dose group only, there are 25 deaths avoided each year, 512 years of life lost (YLL) avoided, and 379,482 sick days avoided.

Across Outer London, this would rise to 480.81 deaths avoided annually, and 9446.50 YLL avoided, due to physical activity from the extra walking and cycling. Across the 20-year appraisal period, and rounding to the nearest million this generates economic benefits of $£ 558$ million (high-dose group only) and $£ 10,297$ million (all Outer London) from physical activity, and $£ 166$ million and $£ 2678$ million respectively from reduced sickness absence.

\section{Discussion}

\subsection{Summary of findings}

This study, with three years' follow-up, provides evidence that Outer London's mini-Holland interventions have led to sustained increases in active travel. Most observed effects are higher closer to interventions (high-dose area or under $2 \mathrm{~km}$ from routes, compared to low-dose area or $2-5 \mathrm{~km}$ from routes), increasing confidence that the changes were caused by the intervention. The general magnitude of change in past-week active travel was similar across all three waves, suggesting lifestyle changes were maintained.

These findings are comparable with other research. Goodman et al. found being $1 \mathrm{~km}$ closer (shortest route network distance) to new walking and cycling infrastructure was associated with an increase in active travel of 15.3 min per week after two years. This would imply that living within $2 \mathrm{~km}$ of such a route would mean 30.6 min per week extra active travel. Here, living within $2 \mathrm{~km}$ of a new mini-Holland route was associated with $35.7 \mathrm{~min}$ extra active travel after two years, and a similar 33.0 extra minutes after three years.

We calculated the health economic benefits from physical activity as being in excess of $£ 500$ million for the interventions implemented by Wave 3 (2016-9) and of $£ 12$ billion if the programme were extended such that all Outer Londoners effectively lived in 'high-dose' areas (primarily entailing substantial motor traffic reduction in neighbourhoods, and cycle tracks on main roads). Health economic benefits from sickness absence add around $25 \%$ to these monetised values.

\subsection{Strengths and limitations}

The study provides an unusually long follow-up ( 3 years) with good evidence of sustained impact of increased active travel, and physical activity. It is also rare in covering area-level (motor traffic reduction and calming, alongside local greening) schemes as well as routes. The response rate was however low and the sample not representative of the local population in terms of age and ethnicity, while reported walking and cycling participation was somewhat higher. This skewing was similar in control and intervention boroughs. We may underestimate wider changes in travel behaviour in the boroughs, as Outer London is changing rapidly and miniHolland programmes may have a larger effect on new than existing residents, due to life events being a spur to travel behaviour change (Chatterjee et al., 2013). Our impact modelling approach was deterministic, following UK transport appraisal guidance, and did not include the many sources of uncertainty.

\footnotetext{
${ }^{6}$ This is much lower than the $62-67 \%$ proportions achieving $140+$ minutes of active travel per week because many people vary their amounts of active travel and physical activity from day to day.
} 


\subsection{Interpretations of our findings}

Our findings demonstrate the sustained impact on active travel from ambitious neighbourhood-level changes that substantially reduce and slow motor traffic, alongside high quality cycle routes on main roads. So far, these changes appear to spur increased local walking, despite largely being interpreted as cycling interventions (Aldred et al., 2019). This impact on walking is noteworthy as while there is research on built environment correlates of walking, there are relatively few studies on the impact of built environment interventions on walking levels. It suggests that 'modal filtering' or what are now called 'Low Traffic Neighbourhood' schemes should primarily be seen as walking interventions, which additionally benefit cycling. The smaller changes in cycling (so far) may also be linked to the greater importance of longer-distance infrastructure for cycling journeys, more likely to cross borough boundaries and rely on infrastructure outside 'high-dose' areas.

Mini-Holland programmes are associated with an increased likelihood of meeting both Transport for London's active travel target (140 min/week) and the WHO target of getting at least half an hour of physical activity (from any source) on at least 5 days. However, these changes were not stronger in the high-dose areas and hence there is a weaker case for attributing changes in overall physical activity to specific built environment interventions.

\subsection{Research recommendations}

These findings demonstrate an impact on active travel of substantial built environment interventions. We did not find evidence of differential uptake. Further studies could recruit larger and/or more diverse samples, to explore impacts of new active travel infrastructure on those under-represented in active travel at baseline. We also did not include children in our study, but some of the neighbourhood-level interventions may have substantial impact on children's daily lives, through reducing motor traffic danger. More research on this aspect would be useful.

\subsection{Policy recommendations}

These findings provide confidence that even in more car-dependent, suburban areas, active travel infrastructure can spur take-up, and that such growth can provide high health economic benefits in relation to intervention costs. Policy-makers should not however necessarily expect this take-up to immediately appear as increases in cycling; initially, active travel growth may manifest itself as increased local walking. Hence policy-makers should monitor changes in walking levels, which are often left uncounted; and (especially given controversy over cycling interventions) highlight the likely impacts of mini-Holland type interventions on walking.

\section{Financial disclosure}

The study was funded by Transport for London. The research is an independent academic project and TfL had no input into this paper apart from to confirm the approximate amount of spending by Wave 3 .

\section{CRediT authorship contribution statement}

Rachel Aldred: Conceptualization, Methodology, Investigation, Data curation, Writing - original draft, Writing - review \& editing, Visualization, Supervision, Project administration, Funding acquisition. James Woodcock: Methodology, Formal analysis, Investigation, Writing - review \& editing, Visualization. Anna Goodman: Methodology, Formal analysis, Investigation, Data curation, Writing - original draft, Writing - review \& editing, Writing - review \& editing, Visualization.

\section{Appendix 1}

\section{Weighting}

The mini-Holland and non mini-Holland groups differed in terms of the proportion of participants coming from different sampling sources (Household leaflet survey, Oyster database, Cyclist database, and Unknown database). The disproportionality of the sampling sources was adjusted in two stages - via group weighting and individual-level weighting. Group level weights were applied to the non mini-Holland group to equalise the relative contribution of different sources. The Unknown sample was a mixture of individuals from the Oyster and Cyclist databases, and the balance between the two groups was likely to be different in the mini-Holland group and in the non mini-Holland group, as we knew that there were proportionally more from the Cyclist database in the non mini-Holland group, and proportionally more from the Oyster database in the mini-Holland group. To take account of this, we further assigned individual weights for the unknown group, separately for cyclists and non-cyclists.

At Wave 1, Wave 2 and Wave 3, these four sources differed in their follow-up rate, and we therefore updated our Baseline weight to take account of that. We did this as follows:

Wave $1 \mathrm{wt}=$ Baseline weight $\times$ Overall Wave 1 follow-up rate.

Wave 1 follow-up rate for source in question.

Wave $2 \mathrm{wt}=$ Baseline weight $\times$ Overall Wave 2 follow-up rate. 
Wave 2 follow-up rate for source in question.

Wave $3 \mathrm{wt}=$ Baseline weight $\times$ Overall Wave 3 follow-up rate.

Wave 3 follow-up rate for source in question.

For example, in the household leaflet sample the Wave 1 follow-up rate was $42 \%$, as opposed to $50 \%$ for the sample as a whole. We therefore multiplied the Baseline weight by $50 \% / 42 \%=1.19$ (Table A1, row C).

The Baseline group-level weight, Baseline individual-level weight and Wave $1 \mathrm{wt}$ were then multiplied together to create a final weight, as summarised in Table A1. An analogous process was used to calculate the Wave 2 and Wave 3 weights.

We compared the characteristics of Wave 1, 2 and 3 participants with those of the background population, where comparison data were available. Within both mini-Holland and non-mini-Holland areas, the sample was fairly representative with respect to gender, but there was a marked underrepresentation of 16-24-year-olds and non-White individuals. In addition, like at Baseline, there was some underrepresentation in the Wave 1, 2 and 3 samples of individuals not in employment and households with no car or van.

Part of the reason for the underrepresentation of individuals not in employment seems to be the use of the Oyster and Cyclist databases when sampling: this under-representation was smaller in the household leaflet sample. Otherwise these effects appeared to reflect differential response rates in the Baseline survey subsequently compounded by the lower follow-up rate among young adults and non-White individuals. Encouragingly, the nature and magnitude of any underrepresentation seemed similar in the mini-Holland and non-mini-Holland groups, suggesting that comparisons between groups may be robust even if the samples are not fully representative of the local population. The only exceptions were a slightly higher proportion of women in the mini-Holland group in Waves 1 and 2 (e.g. 53\% versus 48\% in Wave 1); and lower car ownership in the mini-Holland group in Wave 1 and Wave 3 (e.g. $71 \%$ versus $79 \%$ with any car or van in household in Wave 1$)^{7}$

By contrast, all three Waves saw marked demographic and socio-economic differences within the mini-Holland group in terms of who lived in stakeholder-identified 'high-dose' areas. Those living in high-dose areas were far more likely to be from Waltham Forest and far less likely to be from Enfield. In addition, they were more likely than those in low-dose areas to be: female (e.g. 58\% versus $49 \%$ in Wave 1); younger ( $42 \%$ aged under 45 versus $30 \%$ in Wave 1 ); single adults ( $44 \%$ versus $31 \%$ in Wave 1 ); in full-time employment (65\% versus $53 \%$ in Wave 1 ); and without any household car or van ( $43 \%$ versus $20 \%$ in Wave 1 ). There were no differences by sampling source, ethnicity or disability status. All findings were very similar in Wave 2 and Wave 3. Similar trends were seen when restricting the analyses to Waltham Forest, suggesting that these differences reflected characteristics of high-dose areas in each borough (e.g. housing type). These differences indicate the importance of adjusting for these participant demographic and socio-economic characteristics when comparing the high-dose and low-dose mini-Holland areas.

\section{Baseline travel and physical activity behaviour}

Table A2 below presents baseline levels of travel and physical activity for the Wave 1 sample only (as around half the baseline sample did not participate in future waves). This shows for instance the somewhat higher levels of cycling in Waltham Forest than the non-mini-Holland group, and conversely lower levels than elsewhere in Enfield; this reflects broader population differences.

\section{Differential follow-up according to demographic and socio-economic characteristics, and baseline cycling}

In mutually adjusted analyses there was evidence in all three Waves of a lower follow-up rate for younger participants (e.g. 23\% for those aged $16-24$ versus $\geq 40 \%$ for all older groups in Wave $1, \mathrm{p}<0.001$ ). Non-white participants had lower follow-up than white participants (e.g. $37 \%$ vs. $53 \%$ in Wave $1, \mathrm{p}<0.001$ ). Single adults living with other adults had lower follow-up rates than other groups (e.g. $37 \%$ vs. $\geq 44 \%$ for all other groups in Wave $1, p=0.002$ ). There was no evidence in any Wave of differential follow-up by gender, disability status or car ownership (all p $>0.25$ in adjusted analyses). These differences existed to a similar extent regardless of miniHolland status.

\section{Table A1}

Summary of calculation of weights. Sample characteristics and representativeness.

\begin{tabular}{|c|c|c|c|c|c|}
\hline & & Household leaflet & Oyster database & Cyclist database & Unknown (Oyster or Cyclist database) \\
\hline \multirow[t]{2}{*}{ Column \% of participants at Baseline } & non-MH & $31.1 \%$ & $19.9 \%$ & $36.4 \%$ & $12.6 \%$ \\
\hline & MH & $37.6 \%$ & $32.5 \%$ & $19.6 \%$ & $10.3 \%$ \\
\hline$\%$ followed-up at Wave 1 & non-MH + MH & $41.9 \%$ & $52.3 \%$ & $62.1 \%$ & $36.8 \%$ \\
\hline$\%$ followed-up at Wave 2 & non-MH + MH & $38.5 \%$ & $48.2 \%$ & $58.7 \%$ & $38.9 \%$ \\
\hline$\%$ followed-up at Wave 3 & non-MH + MH & $36.6 \%$ & $45.6 \%$ & $53.9 \%$ & $34.1 \%$ \\
\hline \multirow[t]{2}{*}{ Group-level Baseline weight (A) } & non-MH & 1.21 & 1.63 & 0.54 & 0.82 \\
\hline & MH & 1.00 & 1.00 & 1.00 & 1.00 \\
\hline \multirow[t]{2}{*}{ Individual-level weight (B) } & non-MH & 1.00 & 1.00 & 1.00 & 0.76 cyclists 1.05 non-cyclists \\
\hline & MH & 1.00 & 1.00 & 1.00 & 1.00 \\
\hline
\end{tabular}

\footnotetext{
${ }^{7}$ Where regression analyses are presented, comparing the two groups, we present adjusted analyses that include gender and car ownership as covariates and so adjust for the potential effects of these small differences in the composition of the two groups.
} 
Table A1 (continued)

\begin{tabular}{|c|c|c|c|c|c|}
\hline & & Household leaflet & Oyster database & Cyclist database & Unknown (Oyster or Cyclist database) \\
\hline Wave 1 wt (C) & non-MH + MH & 1.19 & 0.95 & 0.80 & 1.35 \\
\hline Wave 2 wt (D) & non-MH + MH & 1.21 & 0.97 & 0.80 & 1.21 \\
\hline Wave 3 wt (E) & non-MH + MH & 1.19 & 0.96 & 0.81 & 1.28 \\
\hline \multirow[t]{2}{*}{ Wave 1 final weight $(A \times B * C)$} & non-MH & 1.44 & 1.55 & 0.43 & 0.84 cyclists 1.18 non-cyclists \\
\hline & MH & 1.19 & 0.95 & 0.80 & 1.35 \\
\hline \multirow[t]{2}{*}{ Wave 2 final weight $\left(A \times B^{*} D\right)$} & non-MH & 1.47 & 1.58 & 0.43 & 0.75 cyclists 1.05 non-cyclists \\
\hline & MH & 1.21 & 0.97 & 0.80 & 1.21 \\
\hline \multirow[t]{2}{*}{ Wave 3 final weight $(A \times B * E)$} & non-MH & 1.44 & 1.56 & 0.44 & 0.80 cyclists 1.10 non-cyclists \\
\hline & MH & 1.19 & 0.96 & 0.81 & 1.28 \\
\hline
\end{tabular}

Table A2

Travel and physical activity behaviour in the past week at baseline.

\begin{tabular}{|c|c|c|c|c|c|c|c|c|}
\hline & $\begin{array}{l}\text { \% doing } \\
\text { any } \\
\text { cycling }\end{array}$ & $\begin{array}{l}\text { Minutes of } \\
\text { cycling }\end{array}$ & $\begin{array}{l}\% \text { doing } \\
\text { any } \\
\text { walking }\end{array}$ & $\begin{array}{l}\text { Minutes of } \\
\text { walking }\end{array}$ & $\begin{array}{l}\% \text { doing any } \\
\text { cycling or } \\
\text { walking }\end{array}$ & $\begin{array}{l}\% \text { doing } 140+ \\
\text { minutes cycling or } \\
\text { walking }\end{array}$ & $\begin{array}{l}\text { Minutes of } \\
\text { cycling or } \\
\text { walking }\end{array}$ & $\begin{array}{l}\% \text { doing } 30+ \\
\text { minutes PA on at } \\
\text { least } 5 \text { days }\end{array}$ \\
\hline $\begin{array}{l}\text { Non-mini- } \\
\text { Holland }\end{array}$ & $18.2 \%$ & 35.6 & $84.4 \%$ & 204.9 & $86.8 \%$ & $61.5 \%$ & 240.5 & $32.2 \%$ \\
\hline Mini-Holland & $19.2 \%$ & 45.2 & $90.5 \%$ & 236.2 & $92.8 \%$ & $69.5 \%$ & 281.4 & $34.1 \%$ \\
\hline $\begin{array}{l}\text { Non-mini- } \\
\text { Holland }\end{array}$ & $18.2 \%$ & 35.6 & $84.4 \%$ & 204.9 & $86.8 \%$ & $61.5 \%$ & 240.5 & $32.2 \%$ \\
\hline $\begin{array}{l}\text { Waltham } \\
\text { Forest }\end{array}$ & $21.5 \%$ & 52.7 & $92.8 \%$ & 236.7 & $93.9 \%$ & $72.5 \%$ & 289.4 & $38.2 \%$ \\
\hline Kingston & $20.2 \%$ & 44.8 & $90.4 \%$ & 259.0 & $94.1 \%$ & $71.4 \%$ & 303.8 & $35.7 \%$ \\
\hline Enfield & $14.4 \%$ & 34.1 & $87.2 \%$ & 208.6 & $89.6 \%$ & $62.5 \%$ & 242.7 & $25.8 \%$ \\
\hline $\begin{array}{l}\text { Non-mini- } \\
\text { Holland }\end{array}$ & $18.2 \%$ & 35.6 & $84.4 \%$ & 204.9 & $86.8 \%$ & $61.5 \%$ & 240.5 & $32.2 \%$ \\
\hline $\begin{array}{l}\text { Low-dose } \\
\text { Mini- } \\
\text { Holland }\end{array}$ & $17.0 \%$ & 41.8 & $89.9 \%$ & 230.8 & $92.4 \%$ & $64.9 \%$ & 272.7 & $30.2 \%$ \\
\hline $\begin{array}{l}\text { High-dose } \\
\text { Mini- } \\
\text { Holland }\end{array}$ & $22.9 \%$ & 50.7 & $91.6 \%$ & 244.8 & $93.4 \%$ & $77.0 \%$ & 295.5 & $40.5 \%$ \\
\hline
\end{tabular}

Analyses conducted using the Wave 1 sample, with $\mathrm{N}=1712$ for percentages, $\mathrm{N}=1634$ for minutes of travel. All behaviours are for the reference period 'in the past week'.

Table A3

Predictors of Wave 1 cycling.

\begin{tabular}{|c|c|c|c|c|c|c|}
\hline & \multicolumn{3}{|c|}{$\%$ doing any cycling in the past week $(\mathrm{N}=1712)$} & \multicolumn{3}{|c|}{ Minutes of cycling in the past week $(\mathrm{N}=1634)$} \\
\hline & $\%$ & $\begin{array}{l}\text { Minimally-adjusted } \\
\text { rate ratio }(95 \% \mathrm{CI})\end{array}$ & $\begin{array}{l}\text { Additionally-adjusted } \\
\text { rate ratio }(95 \% \mathrm{CI})\end{array}$ & Mean & $\begin{array}{l}\text { Minimally-adjusted } \\
\text { regression coefficient (95\% } \\
\text { CI) }\end{array}$ & $\begin{array}{l}\text { Additionally-adjusted } \\
\text { regression coefficient }(95 \% \mathrm{CI})\end{array}$ \\
\hline $\begin{array}{l}\text { Non-mini- } \\
\text { Holland }\end{array}$ & $15.2 \%$ & 1 & 1 & 29.9 & 0 & 0 \\
\hline Mini-Holland & $18.4 \%$ & $1.17(1.00,1.38) \dagger$ & $1.16(0.99,1.36) \dagger$ & 40.8 & $4.4(-3.7,12.5) \mathrm{a}$ & $4.1(-4.0,12.2)$ \\
\hline $\begin{array}{l}\text { Non-mini- } \\
\text { Holland }\end{array}$ & $15.2 \%$ & 1 & 1 & 29.9 & 0 & 0 \\
\hline Waltham Forest & $20.5 \%$ & $1.20(1.00,1.45) \dagger$ & $1.19(0.98,1.45) \dagger$ & 50.1 & $7.2(-3.8,18.2)$ & $6.1(-5.3,17.5)$ \\
\hline Kingston & $20.3 \%$ & $1.24(0.99,1.55) \dagger$ & $1.25(0.99,1.58) \dagger$ & 42.2 & $5.1(-7.2,17.5)$ & $4.9(-7.5,17.3)$ \\
\hline Enfield & $12.7 \%$ & $0.99(0.72,1.36)$ & $0.97(0.71,1.33)$ & 24.8 & $-0.9(-16.8,15.1)$ & $0.3(-16.2,16.9)$ \\
\hline $\begin{array}{l}\text { Non-mini- } \\
\text { Holland }\end{array}$ & $15.2 \%$ & 1 & 1 & 29.9 & 0 & 0 \\
\hline $\begin{array}{l}\text { Low-dose Mini- } \\
\text { Holland }\end{array}$ & $15.9 \%$ & $1.10(0.91,1.33)$ & $1.10(0.90,1.34)$ & 34.0 & $0.9(-9.0,10.8)$ & $1.4(-8.5,11.2)$ \\
\hline $\begin{array}{l}\text { High-dose Mini- } \\
\text { Holland }\end{array}$ & $22.4 \%$ & $1.25(1.03,1.53)^{*}$ & $1.24(1.02,1.52)^{*}$ & 51.9 & $10.1(-1.6,21.7) \dagger$ & $8.9(-3.1,20.8)$ \\
\hline
\end{tabular}


Table A4

Predictors of Wave 2 cycling.

\begin{tabular}{|c|c|c|c|c|c|c|}
\hline & \multicolumn{3}{|c|}{$\%$ doing any cycling in the past week $(\mathrm{N}=1610)$} & \multicolumn{3}{|c|}{ Minutes of cycling in the past week $(\mathrm{N}=1444)$} \\
\hline & $\% \mathrm{a}$ & $\begin{array}{l}\text { Minimally-adjusted } \\
\text { rate ratio }(95 \% \mathrm{CI})\end{array}$ & $\begin{array}{l}\text { Additionally-adjusted } \\
\text { rate ratio }(95 \% \mathrm{CI})\end{array}$ & Mean & $\begin{array}{l}\text { Minimally-adjusted } \\
\text { regression coefficient } \\
(95 \% \mathrm{CI})\end{array}$ & $\begin{array}{l}\text { Additionally-adjusted } \\
\text { regression coefficient (95\% } \\
\text { CI) }\end{array}$ \\
\hline Non-mini-Holland & $16.2 \%$ & 1 & 1 & 33.5 & 0 & 0 \\
\hline Mini-Holland & $16.8 \%$ & $1.03(0.86,1.23)$ & $1.04(0.87,1.24)$ & 31.9 & $-2.2(-10.0,5.6)$ & $-2.0(-9.8,5.8)$ \\
\hline Non-mini-Holland & $16.2 \%$ & 1 & 1 & 33.5 & 0 & 0 \\
\hline Waltham Forest & $18.2 \%$ & $1.09(0.86,1.39)$ & $1.10(0.86,1.41)$ & 36.4 & $1.2(-10.0,12.4)$ & $1.6(-9.3,12.4)$ \\
\hline Kingston & $21.6 \%$ & $1.12(0.89,1.40)$ & $1.15(0.91,1.44)$ & 40.4 & $-0.7(-13.1,11.7)$ & $-0.5(-13.1,12.1)$ \\
\hline Enfield & $9.3 \%$ & $0.75(0.54,1.05) \dagger$ & $0.74(0.53,1.03) \dagger$ & 15.6 & $-8.9(-16.7,-1.1)^{*}$ & $-8.7(-16.6,-0.8)^{*}$ \\
\hline Non-mini-Holland & $16.2 \%$ & 1 & 1 & 33.5 & 0 & 0 \\
\hline Low-dose Mini-Holland & $14.8 \%$ & $0.97(0.79,1.20)$ & $0.98(0.79,1.22)$ & 27.1 & $-1.7(-11.2,7.8)$ & $-1.7(-11.2,7.8)$ \\
\hline High-dose Mini-Holland & $19.7 \%$ & $1.10(0.88,1.38)$ & $1.11(0.88,1.40)$ & 38.7 & $-2.4(-13.0,8.2)$ & $-2.4(-13.0,8.2)$ \\
\hline$\geq 5 \mathrm{~km}$ from routes & $15.4 \%$ & 1 & 1 & 30.2 & 0 & 0 \\
\hline $2-4.9 \mathrm{~km}$ from routes & $15.4 \%$ & $1.13(0.90,1.41)$ & $1.07(0.85,1.34)$ & 29.4 & $2.4(-6.5,11.3)$ & $2.7(-6.2,11.6)$ \\
\hline$<2 \mathrm{~km}$ from routes & $20.0 \%$ & $1.12(0.92,1.38)$ & $1.16(0.95,1.43)$ & 42.3 & $2.3(-8.3,12.9)$ & $3.7(-7.1,14.5)$ \\
\hline $\begin{array}{l}\text { Change per } \mathrm{km} \text { decrease in } \\
\text { distance from routes ( } \mathrm{MH} \\
\text { group only) }\end{array}$ & - & $1.05(0.96,1.14)$ & $1.06(0.97,1.17)$ & - & $0.4(-2.6,3.5)$ & $0.9(-2.3,4.2)$ \\
\hline
\end{tabular}

See footnote to Table A3.

\section{Table A5}

Predictors of Wave 3 cycling.

\begin{tabular}{|c|c|c|c|c|c|c|}
\hline & \multicolumn{4}{|c|}{$\%$ doing any cycling in the past week $(\mathrm{N}=1498)$} & \multicolumn{2}{|c|}{ Minutes of cycling in the past week $(\mathrm{N}=1498)$} \\
\hline & $\%$ & $\begin{array}{l}\text { Minimally-adjusted } \\
\text { rate ratio }(95 \% \mathrm{CI})\end{array}$ & $\begin{array}{l}\text { Additionally-adjusted } \\
\text { rate ratio }(95 \% \mathrm{CI})\end{array}$ & Mean & $\begin{array}{l}\text { Minimally-adjusted } \\
\text { regression coefficient } \\
(95 \% \mathrm{CI})\end{array}$ & $\begin{array}{l}\text { Additionally-adjusted } \\
\text { regression coefficient (95\% } \\
\text { CI) }\end{array}$ \\
\hline Non-mini-Holland & $13.9 \%$ & 1 & 1 & 26.6 & 0 & 0 \\
\hline Mini-Holland & $17.7 \%$ & $1.16(0.96,1.40)$ & $1.18(0.98,1.42) \dagger$ & 39.4 & $5.3(-2.9,13.6)$ & $5.4(-3.2,14.0)$ \\
\hline Non-mini-Holland & $13.9 \%$ & 1 & 1 & 26.6 & 0 & 0 \\
\hline Waltham Forest & $21.8 \%$ & $1.48(1.19,1.84)^{* * *}$ & $1.49(1.18,1.89)^{* *}$ & 40.5 & $8.2(-1.5,17.9) \dagger$ & $7.8(-2.3,17.9)$ \\
\hline Kingston & $20.1 \%$ & $1.11(0.87,1.42)$ & $1.17(0.91,1.49)$ & 52.0 & $13.9(-3.2,30.9)$ & $14.8(-3.1,32.7)$ \\
\hline Enfield & $8.5 \%$ & $0.66(0.43,1.01) \dagger$ & $0.66(0.44,1.00) \dagger$ & 22.2 & $-9.6(-20.2,1.0) \dagger$ & $-9.8(-20.4,0.8) \dagger$ \\
\hline Non-mini-Holland & $13.9 \%$ & 1 & 1 & 26.6 & 0 & 0 \\
\hline Low-dose Mini-Holland & $13.7 \%$ & $0.96(0.75,1.25)$ & $1.00(0.78,1.28)$ & 28.3 & $-2.4(-11.6,6.8)$ & $-1.5(-10.8,7.9)$ \\
\hline High-dose Mini-Holland & $22.3 \%$ & $1.35(1.10,1.65)^{* *}$ & $1.35(1.09,1.67)^{* *}$ & 51.8 & $14.0(1.7,26.4)^{*}$ & $13.3(1.0,25.6)^{*}$ \\
\hline$\geq 5 \mathrm{~km}$ from routes & $13.3 \%$ & 1 & 1 & 24.9 & 0 & 0 \\
\hline $2-4.9 \mathrm{~km}$ from routes & $11.3 \%$ & $0.86(0.62,1.19)$ & $0.91(0.66,1.25)$ & 22.7 & $-3.6(-13.7,6.6)$ & $-2.8(-12.7,7.2)$ \\
\hline$<2 \mathrm{~km}$ from routes & $21.3 \%$ & $1.30(1.06,1.59)^{*}$ & $1.30(1.06,1.61)^{*}$ & 48.4 & $10.9(1.1,20.7)^{*}$ & $10.6(0.7,20.4)^{*}$ \\
\hline $\begin{array}{l}\text { Change per km decrease in } \\
\text { distance from routes } \\
\text { (MH group only) }\end{array}$ & - & $1.07(0.94,1.21)$ & $1.06(0.94,1.18)$ & - & $4.7(0.3,9.1)^{*}$ & $3.0(-0.2,6.2) \dagger$ \\
\hline
\end{tabular}

See footnote to Table A3.

\section{Table A6}

Predictors of Wave 1 walking.

\begin{tabular}{|c|c|c|c|c|c|c|}
\hline & \multicolumn{3}{|c|}{$\%$ doing any walking in the past week $(\mathrm{N}=1712)$} & \multicolumn{3}{|c|}{ Minutes of walking in the past week $(\mathrm{N}=1634)$} \\
\hline & $\%$ & $\begin{array}{l}\text { Minimally-adjusted } \\
\text { rate ratio }(95 \% \mathrm{CI})\end{array}$ & $\begin{array}{l}\text { Additionally-adjusted } \\
\text { rate ratio }(95 \% \mathrm{CI})\end{array}$ & Mean & $\begin{array}{l}\text { Minimally-adjusted } \\
\text { regression coefficient (95\% } \\
\text { CI) }\end{array}$ & $\begin{array}{l}\text { Additionally-adjusted } \\
\text { regression coefficient ( } 95 \% \mathrm{CI})\end{array}$ \\
\hline $\begin{array}{l}\text { Non-mini- } \\
\text { Holland }\end{array}$ & $82.9 \%$ & 1 & 1 & 203.1 & 0 & 0 \\
\hline Mini-Holland & $87.6 \%$ & $1.03(0.99,1.08)$ & $1.03(0.98,1.07)$ & 240.9 & $24.8(3.7,45.9)^{*}$ & $19.0(-1.8,39.8) \dagger$ \\
\hline $\begin{array}{l}\text { Non-mini- } \\
\text { Holland }\end{array}$ & $82.9 \%$ & 1 & 1 & 203.1 & 0 & 0 \\
\hline Waltham Forest & $87.2 \%$ & $1.02(0.97,1.08)$ & $1.00(0.95,1.05)$ & 245.0 & $24.6(-2.9,52.2) \dagger$ & $12.4(-15.4,40.1)$ \\
\hline Kingston & $89.3 \%$ & $1.05(1.00,1.11) \dagger$ & $1.06(1.00,1.12)^{*}$ & 258.3 & $31.7(-2.1,65.4) \dagger$ & $33.3(0.2,66.4)^{*}$ \\
\hline Enfield & $86.1 \%$ & $1.03(0.96,1.10)$ & $1.02(0.96,1.09)$ & 213.9 & $17.2(-13.9,48.3)$ & $12.3(-18.7,43.3)$ \\
\hline $\begin{array}{l}\text { Non-mini- } \\
\text { Holland }\end{array}$ & $82.9 \%$ & 1 & 1 & 203.1 & 0 & 0 \\
\hline $\begin{array}{l}\text { Low-dose Mini- } \\
\text { Holland }\end{array}$ & $87.0 \%$ & $1.03(0.98,1.08)$ & $1.03(0.98,1.08)$ & 222.6 & $12.1(-10.9,35.1)$ & $11.4(-11.5,34.4)$ \\
\hline $\begin{array}{l}\text { High-dose Mini- } \\
\text { Holland }\end{array}$ & $88.6 \%$ & $1.04(0.99,1.10)$ & $1.02(0.97,1.08)$ & 270.4 & $45.4(13.5,77.3)^{* *}$ & $32.0(-0.1,64.1) \dagger$ \\
\hline
\end{tabular}

See footnote to Table A3. 
Table A7

Predictors of Wave 2 walking.

$\%$ doing any walking in the past week $(\mathrm{N}=1610)$

$\% \quad$ Minimally-adjusted Additionally-adjusted rate ratio $(95 \% \mathrm{CI}) \quad$ rate ratio $(95 \% \mathrm{CI})$
Minutes of walking in the past week $(\mathrm{N}=1444)$

Mean Minimally-adjusted Additionally-adjusted

regression coefficient $(95 \%$ CI)

219.80

$261.930 .3(8.5,52.1)^{* * *}$

$219.8 \quad 0$

$282.948 .2(17.1,79.4)^{* *}$

$256.120 .1(-12.5,52.7)$

$238.716 .6(-15.7,48.9)$

$219.8 \quad 0$

$238.1 \quad 13.7(-11.1,38.5)$

$295.754 .0(23.1,84.9)^{* *}$ $220.1 \quad 0$

$232.318 .7(-8.3,45.8)$

$286.936 .5(9.4,63.6)^{* * *}$

- $\quad 14.8(5.0,24.7)$ CI)

0
$26.3(4.8,47.9)^{*}$
0
$42.5(10.7,74.4)^{* *}$
$17.5(-15.3,50.2)$
$14.1(-18.4,46.5)$
0
$13.1(-11.8,38.0)$
$45.7(14.3,77.1)^{* *}$
0
$21.8(-5.0,48.5)$
$30.9(3.8,58.0)^{*}$
$11.8(0.9,22.6)$

$<2 \mathrm{~km}$ from routes

Change per km decrease in distance from routes (MH group only)

See footnote to Table A3.

\section{Table A8}

Predictors of Wave 3 walking.

$\%$ doing any walking in the past week $(\mathrm{N}=1498)$

$\% \quad$ Minimally-adjusted Additionally-adjusted rate ratio $(95 \% \mathrm{CI}) \quad$ rate ratio $(95 \% \mathrm{CI})$
Minutes of walking in the past week $(\mathrm{N}=1498)$

Mean Minimally-adjusted Additionally-adjusted

regression coefficient (95\% regression coefficient (95\% CI)

Non-mini-Holland
Mini-Holland
Non-mini-Holland
Waltham Forest
Kingston
Enfield
Non-mini-Holland
Low-dose Mini-Holland
High-dose Mini-Holland
$\geq 5$ km from routes
$2-4.9$ km from routes
$<2$ km from routes
Change per km decrease in
$\quad$ distance from routes $(\mathrm{MH}$
$\quad$ group only)

$\begin{array}{lll}85.0 \% & 1 & 1 \\ 88.1 \% & 1.02(0.98,1.06) & 1.02(0.98,1.06) \\ 85.0 \% & 1 & 1 \\ 91.9 \% & 1.06(1.01,1.11) * & 1.06(1.01,1.11) \\ 85.7 \% & 1.00(0.94,1.06) & 1.00(0.94,1.06) \\ 85.0 \% & 0.99(0.92,1.06) & 0.99(0.93,1.06) \\ 85.0 \% & 1 & 1 \\ 85.8 \% & 1.00(0.95,1.05) & 1.00(0.95,1.06) \\ 90.6 \% & 1.05(1.00,1.10) \dagger & 1.04(0.99,1.09) \\ 85.0 \% & 1 & 1 \\ 86.0 \% & 1.00(0.94,1.06) & 1.01(0.94,1.07) \\ 88.7 \% & 1.03(0.98,1.08) & 1.02(0.98,1.07) \\ - & 1.01(0.99,1.02) & 1.01(0.99,1.02)\end{array}$

$228.0 \quad 0$

$260.315 .7(-11.0,42.3)$

228.00

$274.521 .9(-14.1,57.8)$

$244.2-3.4(-36.7,29.9)$

$258.029 .4(-15.7,74.6)$

$228.0 \quad 0$

$226.8-1.8(-31.7,28.0)$

$297.735 .7(-0.3,71.7) \dagger$

229.60

$215.1-21.2(-53.3,10.8)$

$277.725 .3(-6.7,57.2)$

- $22.1(8.8,35.3)^{* * *}$
CI)

0
$13.6(-13.1,40.3)$
0
$17.1(-19.7,53.9)$
$-3.5(-37.3,30.2)$
$29.2(-16.0,74.4)$
0
$0.8(-30.3,32.0)$
$28.5(-8.0,65.1)$
0
$-14.2(-46.6,18.3)$
$21.6(-9.1,52.3)$
$7.3(-5.0,19.5)$

Table A9

Predictors of Wave 1 active travel (cycling or walking).

$\%$ doing any cycling or walking in the past week \% doing $140+$ minutes cycling or walking in $(\mathrm{N}=1712)$ the past week $(\mathrm{N}=1634)$

$\begin{array}{ll}\text { Minimally- } & \begin{array}{l}\text { Additionally- } \\ \text { adjusted rate ratio }\end{array} \\ \text { ratio }(95 \% \mathrm{CI}) & (95 \% \mathrm{CI})\end{array}$

Minutes of cycling or walking in the past week $(\mathrm{N}=1634)$

Mean Minimally- Additionally-
adjusted regression adjusted regression coefficient $(95 \%$ coefficient $(95 \% \mathrm{CI})$ CI)

\begin{tabular}{|c|c|c|c|c|c|c|c|c|c|}
\hline $\begin{array}{l}\text { Non-mini- } \\
\text { Holland }\end{array}$ & $85.3 \%$ & 1 & 1 & $57.4 \%$ & 1 & 1 & 233.0 & 0 & 0 \\
\hline $\begin{array}{l}\text { Mini- } \\
\text { Holland }\end{array}$ & $90.0 \%$ & $\begin{array}{l}1.03(0.99 \\
1.07) \dagger\end{array}$ & $1.03(0.99,1.07)$ & $68.6 \%$ & $\begin{array}{l}1.14(1.06 \\
1.23)^{* *}\end{array}$ & $1.12(1.04,1.21)^{* *}$ & 281.7 & $28.3(6.1,50.1)^{*}$ & $23.0(1.0,44.9)^{*}$ \\
\hline $\begin{array}{l}\text { Non-mini- } \\
\text { Holland }\end{array}$ & $85.3 \%$ & 1 & 1 & $57.4 \%$ & 1 & 1 & 233.0 & 0 & 0 \\
\hline $\begin{array}{l}\text { Waltham } \\
\text { Forest }\end{array}$ & $89.2 \%$ & $1.02(0.97,1.07)$ & $1.00(0.96,1.05)$ & $70.9 \%$ & $\begin{array}{l}1.14(1.04 \\
1.25)^{* *}\end{array}$ & $1.10(1.00,1.20)^{*}$ & 295.1 & $31.9(2.2,61.6)^{*}$ & $19.5(-10.5,49.5)$ \\
\hline Kingston & $92.9 \%$ & $\begin{array}{l}1.06(1.01 \\
1.11)^{*}\end{array}$ & $1.06(1.02,1.12)^{* *}$ & $73.9 \%$ & $\begin{array}{l}1.19(1.08 \\
1.31)^{* * *}\end{array}$ & $\begin{array}{l}1.19(1.09 \\
1.31)^{* * *}\end{array}$ & 300.4 & $33.2(-2.2,68.6) \dagger$ & $34.9(-0.1,69.8) \dagger$ \\
\hline Enfield & $87.7 \%$ & $1.02(0.96,1.08)$ & $1.02(0.96,1.08)$ & $58.7 \%$ & $1.07(0.94,1.21)$ & $1.06(0.94,1.20)$ & 238.7 & $17.2(-16.6,51.1)$ & $14.5(-19.7,48.7)$ \\
\hline \multirow[t]{2}{*}{$\begin{array}{l}\text { Non-mini- } \\
\text { Holland }\end{array}$} & $85.3 \%$ & 1 & 1 & $57.4 \%$ & 1 & 1 & 233.0 & 0 & 0 \\
\hline & $89.2 \%$ & $1.03(0.98,1.07)$ & $1.03(0.98,1.07)$ & $64.7 \%$ & $\begin{array}{l}1.11(1.02 \\
1.21)^{*}\end{array}$ & $1.11(1.02,1.21)^{*}$ & 256.5 & $12.3(-12.1,36.7)$ & $12.5(-12.1,37.1)$ \\
\hline
\end{tabular}


Table A9 (continued)

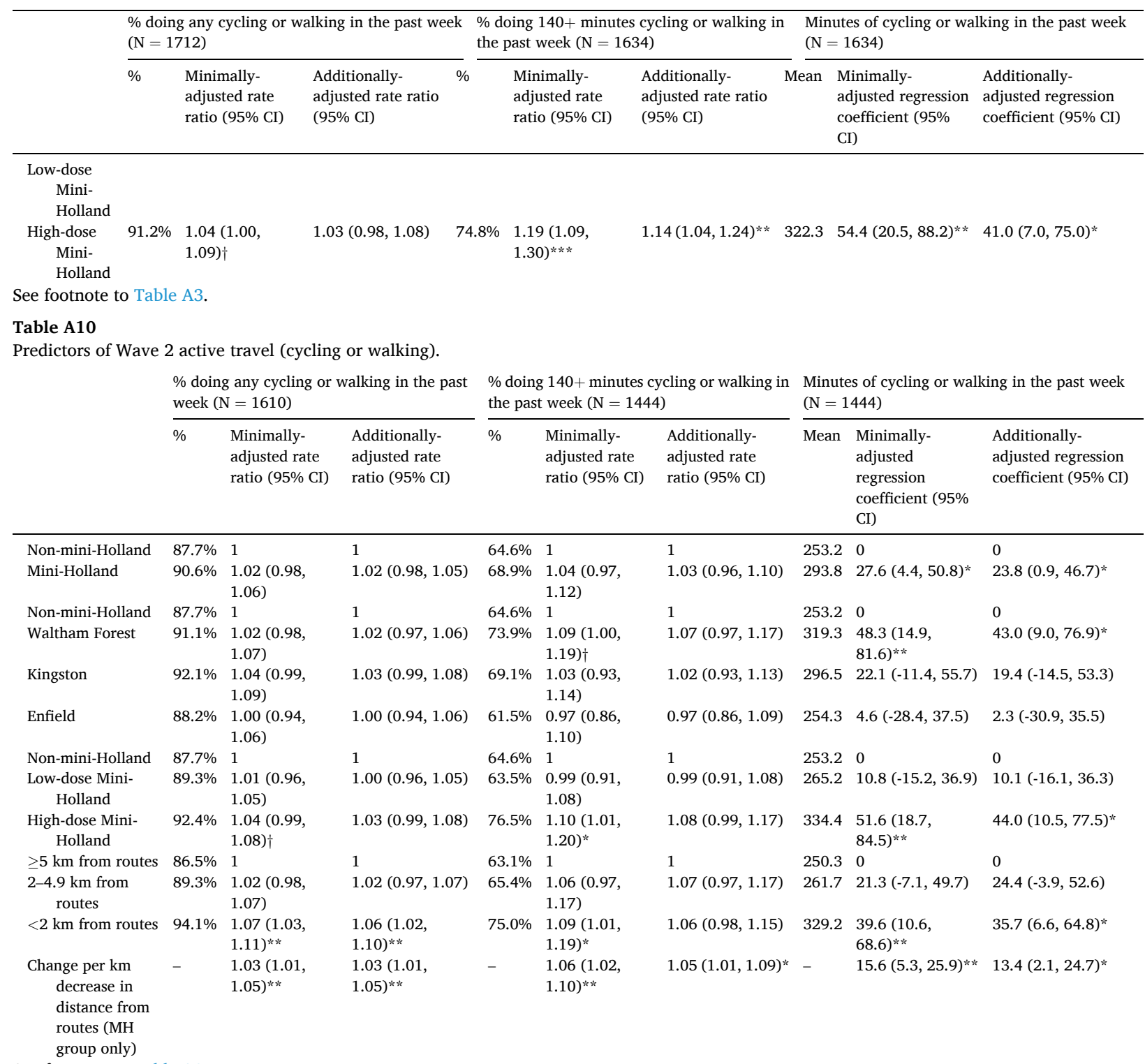

See footnote to Table A3.

\section{Table A11}

Predictors of Wave 3 active travel (cycling or walking).

\begin{tabular}{|c|c|c|}
\hline \multicolumn{3}{|c|}{$\begin{array}{l}\% \text { doing any cycling or walking in the past } \\
\text { week }(\mathrm{N}=1498)\end{array}$} \\
\hline$\%$ & $\begin{array}{l}\text { Minimally- } \\
\text { adjusted rate } \\
\text { ratio } 95 \%\end{array}$ & $\begin{array}{l}\text { Additionally- } \\
\text { adjusted rate } \\
\text { ratio }(95 \% \mathrm{CI})\end{array}$ \\
\hline
\end{tabular}

$\%$ doing $140+$ minutes cycling or walking in the past week $(\mathrm{N}=1498)$

\begin{tabular}{lll}
\hline$\%$ & Minimally- & Additionally- \\
adjusted rate & adjusted rate \\
ratio $(95 \%$ & ratio $(95 \% \mathrm{CI})$ \\
$\mathrm{CI})$ &
\end{tabular}

Minutes of cycling or walking in the past week $(\mathrm{N}=1498)$

Mean Minimally- Additionally-

adjusted adjusted

regression regression

coefficient coefficient (95\% $(95 \% \mathrm{CI}) \quad \mathrm{CI})$

\begin{tabular}{|c|c|c|c|c|c|c|c|c|c|}
\hline $\begin{array}{l}\text { Non-mini- } \\
\text { Holland }\end{array}$ & $87.3 \%$ & 1 & 1 & $61.9 \%$ & 1 & 1 & 254.7 & 0 & 0 \\
\hline Mini-Holland & $89.8 \%$ & $\begin{array}{l}1.01(0.98, \\
1.05)\end{array}$ & $\begin{array}{l}1.01(0.98, \\
1.05)\end{array}$ & $70.6 \%$ & $\begin{array}{l}1.09(1.01 \\
1.17)^{*}\end{array}$ & $\begin{array}{l}1.10 \\
1.18)^{*}\end{array}$ & 299.7 & $\begin{array}{l}20.8(-6.8 \\
48.5)\end{array}$ & $19.2(-8.5,47.0)$ \\
\hline $\begin{array}{l}\text { Non-mini- } \\
\text { Holland }\end{array}$ & $87.3 \%$ & 1 & 1 & $61.9 \%$ & 1 & 1 & 254.7 & 0 & 0 \\
\hline $\begin{array}{l}\text { Waltham } \\
\text { Forest }\end{array}$ & $93.1 \%$ & $\begin{array}{l}1.05(1.00 \\
1.10)^{*}\end{array}$ & $\begin{array}{l}1.05(1.00 \\
1.10)^{*}\end{array}$ & $77.5 \%$ & $\begin{array}{l}1.17(1.07 \\
1.27)^{* * *}\end{array}$ & $\begin{array}{l}1.17(1.07 \\
1.28)^{* * *}\end{array}$ & 315.0 & $\begin{array}{l}27.3(-10.2, \\
64.7)\end{array}$ & $\begin{array}{l}22.8(-15.6 \\
61.1)\end{array}$ \\
\hline
\end{tabular}


Table A11 (continued)

\begin{tabular}{|c|c|c|c|c|c|c|c|c|c|}
\hline & \multicolumn{3}{|c|}{$\begin{array}{l}\% \text { doing any cycling or walking in the past } \\
\text { week }(\mathrm{N}=1498)\end{array}$} & \multicolumn{3}{|c|}{$\begin{array}{l}\% \text { doing } 140+\text { minutes cycling or walking in } \\
\text { the past week }(\mathrm{N}=1498)\end{array}$} & \multicolumn{3}{|c|}{$\begin{array}{l}\text { Minutes of cycling or walking in the past week } \\
(\mathrm{N}=1498)\end{array}$} \\
\hline & $\%$ & $\begin{array}{l}\text { Minimally- } \\
\text { adjusted rate } \\
\text { ratio (95\% } \\
\text { CI) }\end{array}$ & $\begin{array}{l}\text { Additionally- } \\
\text { adjusted rate } \\
\text { ratio }(95 \% \mathrm{CI})\end{array}$ & $\%$ & $\begin{array}{l}\text { Minimally- } \\
\text { adjusted rate } \\
\text { ratio (95\% } \\
\text { CI) }\end{array}$ & $\begin{array}{l}\text { Additionally- } \\
\text { adjusted rate } \\
\text { ratio }(95 \% \mathrm{CI})\end{array}$ & Mean & $\begin{array}{l}\text { Minimally- } \\
\text { adjusted } \\
\text { regression } \\
\text { coefficient } \\
(95 \% \mathrm{CI})\end{array}$ & $\begin{array}{l}\text { Additionally- } \\
\text { adjusted } \\
\text { regression } \\
\text { coefficient (95\% } \\
\text { CI) }\end{array}$ \\
\hline Kingston & $88.5 \%$ & $\begin{array}{l}1.00(0.95 \\
1.06)\end{array}$ & $\begin{array}{l}1.00(0.95 \\
1.06)\end{array}$ & $67.9 \%$ & $\begin{array}{l}1.03(0.93 \\
1.14)\end{array}$ & $\begin{array}{l}1.05(0.94 \\
1.16)\end{array}$ & 296.2 & $\begin{array}{l}10.4(-25.7 \\
46.5)\end{array}$ & $\begin{array}{l}11.5(-25.5 \\
48.4)\end{array}$ \\
\hline Enfield & $86.3 \%$ & $\begin{array}{l}0.97(0.91 \\
1.04)\end{array}$ & $\begin{array}{l}0.98(0.92 \\
1.04)\end{array}$ & $63.4 \%$ & $\begin{array}{l}1.03(0.91 \\
1.17)\end{array}$ & $\begin{array}{l}1.05(0.93 \\
1.18)\end{array}$ & 280.2 & $\begin{array}{l}23.6(-22.1 \\
69.3)\end{array}$ & $\begin{array}{l}23.4(-22.3 \\
69.1)\end{array}$ \\
\hline $\begin{array}{l}\text { Non-mini- } \\
\text { Holland }\end{array}$ & $87.3 \%$ & 1 & 1 & $61.9 \%$ & 1 & 1 & 254.7 & 0 & 0 \\
\hline $\begin{array}{l}\text { Low-dose } \\
\text { Mini- } \\
\text { Holland }\end{array}$ & $87.3 \%$ & $\begin{array}{l}0.99(0.94 \\
1.04)\end{array}$ & $\begin{array}{l}0.99(0.94 \\
1.04)\end{array}$ & $64.6 \%$ & $\begin{array}{l}1.04(0.95 \\
1.15)\end{array}$ & $\begin{array}{l}1.07(0.97, \\
1.17)\end{array}$ & 255.2 & $\begin{array}{l}-3.1(-34.1 \\
27.8)\end{array}$ & $0.3(-31.8,32.5)$ \\
\hline $\begin{array}{l}\text { High-dose } \\
\text { Mini- } \\
\text { Holland }\end{array}$ & $92.6 \%$ & $\begin{array}{l}1.04(1.00 \\
1.09)^{*}\end{array}$ & $\begin{array}{l}1.04(1.00 \\
1.09) \dagger\end{array}$ & $77.3 \%$ & $\begin{array}{l}1.13(1.05 \\
1.23)^{* *}\end{array}$ & $\begin{array}{l}1.13(1.04 \\
1.23)^{* *}\end{array}$ & 349.5 & $\begin{array}{l}48.5(10.9 \\
86.0)^{*}\end{array}$ & $41.5(3.3,79.7)^{*}$ \\
\hline $\begin{array}{c}\geq 5 \mathrm{~km} \text { from } \\
\text { routes }\end{array}$ & $87.0 \%$ & 1 & 1 & $61.3 \%$ & 1 & 1 & 254.5 & 0 & 0 \\
\hline $\begin{array}{l}2-4.9 \mathrm{~km} \text { from } \\
\text { routes }\end{array}$ & $87.5 \%$ & $\begin{array}{l}0.99(0.94, \\
1.05)\end{array}$ & $\begin{array}{l}1.00(0.94 \\
1.06)\end{array}$ & $65.2 \%$ & $\begin{array}{l}1.05(0.94, \\
1.17)\end{array}$ & $\begin{array}{l}1.09(0.98 \\
1.22)\end{array}$ & 237.8 & $\begin{array}{l}-24.9(-58.0 \\
8.2)\end{array}$ & $\begin{array}{l}-17.0(-50.3 \\
16.2)\end{array}$ \\
\hline $\begin{array}{c}<2 \mathrm{~km} \text { from } \\
\text { routes }\end{array}$ & $91.0 \%$ & $\begin{array}{l}1.03(0.99, \\
1.07)\end{array}$ & $\begin{array}{l}1.03(0.99 \\
1.07)\end{array}$ & $72.8 \%$ & $\begin{array}{l}1.10(1.02 \\
1.20)^{*}\end{array}$ & $\begin{array}{l}1.10(1.02 \\
1.20)^{*}\end{array}$ & 326.0 & $\begin{array}{l}36.2(2.9 \\
69.6) *\end{array}$ & $33.0(0.9,65.1)^{*}$ \\
\hline $\begin{array}{l}\text { Change per km } \\
\text { decrease } \\
\text { in distance } \\
\text { from } \\
\text { routes } \\
\text { (MH group } \\
\text { only) }\end{array}$ & - & $\begin{array}{l}1.01(0.99 \\
1.03)\end{array}$ & $\begin{array}{l}1.01(0.99 \\
1.03)\end{array}$ & - & $\begin{array}{l}1.02(0.99 \\
1.06)\end{array}$ & $\begin{array}{l}1.02(0.98 \\
1.06)\end{array}$ & - & $\begin{array}{l}27.3(13.4 \\
41.2)^{* * *}\end{array}$ & $11.0(-2.4,24.4)$ \\
\hline
\end{tabular}

Table A12

Predictors of past-week physical activity at Wave 1 .

\begin{tabular}{llll}
\hline & \multicolumn{2}{l}{$\%$ doing $30+$ minutes PA on at least 5 days in the past week $(\mathrm{N}=1712)$} \\
\cline { 2 - 4 } & $\%$ & 1 & Minimally-adjusted rate ratio $(95 \% \mathrm{CI})$ \\
\hline Non-mini-Holland & $29.0 \%$ & $1.17(1.02,1.34)^{*}$ & 1 \\
Mini-Holland & $34.9 \%$ & 1 & $1.16(1.01,1.33)^{*}$ \\
Non-mini-Holland & $29.0 \%$ & $1.18(1.00,1.39)^{*}$ & 1 \\
Waltham Forest & $36.7 \%$ & $1.19(0.99,1.43) \dagger$ & $1.18(1.00,1.39) \dagger$ \\
Kingston & $36.7 \%$ & $1.11(0.88,1.39)$ & $1.20(0.99,1.44) \dagger$ \\
Enfield & $30.1 \%$ & 1 & $1.08(0.86,1.36)$ \\
Non-mini-Holland & $29.0 \%$ & $1.20(1.02,1.40)^{*}$ & 1 \\
Low-dose Mini-Holland & $34.4 \%$ & $1.12(0.95,1.33)$ & $1.19(1.02,1.40)^{*}$ \\
High-dose Mini-Holland & $35.7 \%$ & $0.92,1.32)$ & $1.10(95 \% \mathrm{CI})$ \\
\hline
\end{tabular}

See footnote to Table A3.

Table A13

Predictors of past-week physical activity at Wave 2 .

\begin{tabular}{|c|c|c|c|}
\hline & \multicolumn{3}{|c|}{$\%$ doing $30+$ minutes PA on at least 5 days in the past week $(\mathrm{N}=1610)$} \\
\hline & $\%$ & $\begin{array}{l}\text { Minimally-adjusted rate ratio }(95 \% \\
\text { CI) }\end{array}$ & $\begin{array}{l}\text { Additionally-adjusted rate ratio (95\% } \\
\text { CI) }\end{array}$ \\
\hline Non-mini-Holland & $30.2 \%$ & 1 & 1 \\
\hline Mini-Holland & $35.6 \%$ & $1.14(0.99,1.30) \dagger$ & $1.14(0.99,1.30) \dagger$ \\
\hline Non-mini-Holland & $30.2 \%$ & 1 & 1 \\
\hline Waltham Forest & $39.4 \%$ & $1.22(1.03,1.45)^{*}$ & $1.25(1.05,1.49)^{*}$ \\
\hline Kingston & $34.7 \%$ & $1.09(0.91,1.31)$ & $1.08(0.90,1.29)$ \\
\hline
\end{tabular}


Table A13 (continued)

\begin{tabular}{|c|c|c|c|}
\hline & \multicolumn{3}{|c|}{$\%$ doing $30+$ minutes PA on at least 5 days in the past week $(\mathrm{N}=1610)$} \\
\hline & $\%$ & $\begin{array}{l}\text { Minimally-adjusted rate ratio (95\% } \\
\mathrm{CI})\end{array}$ & $\begin{array}{l}\text { Additionally-adjusted rate ratio (95\% } \\
\text { CI) }\end{array}$ \\
\hline Enfield & $31.4 \%$ & $1.06(0.86,1.31)$ & $1.04(0.85,1.29)$ \\
\hline Non-mini-Holland & $30.2 \%$ & 1 & 1 \\
\hline Low-dose Mini-Holland & $33.3 \%$ & $1.08(0.92,1.27)$ & $1.08(0.92,1.27)$ \\
\hline High-dose Mini-Holland & $38.9 \%$ & $1.21(1.03,1.43)^{*}$ & $1.21(1.03,1.44)^{*}$ \\
\hline$\geq 5 \mathrm{~km}$ from routes & $31.4 \%$ & 1 & 1 \\
\hline $2-4.9 \mathrm{~km}$ from routes & $31.6 \%$ & $1.07(0.90,1.28)$ & $1.06(0.89,1.26)$ \\
\hline$<2 \mathrm{~km}$ from routes & $37.5 \%$ & $1.14(0.97,1.33)$ & $1.15(0.98,1.35) \dagger$ \\
\hline Change per km decrease in distance from routes ( $\mathrm{MH}$ group only) & - & $1.02(0.96,1.08)$ & $1.02(0.96,1.09)$ \\
\hline
\end{tabular}

See footnote to Table A3.

\section{Table A14}

Predictors of past-week physical activity at Wave 3 .

\begin{tabular}{|c|c|c|c|}
\hline & \multicolumn{3}{|c|}{$\%$ doing $30+$ minutes PA on at least 5 days in the past week $(\mathrm{N}=1498)$} \\
\hline & $\%$ & $\begin{array}{l}\text { Minimally-adjusted rate ratio ( } 95 \% \\
\text { CI) }\end{array}$ & $\begin{array}{l}\text { Additionally-adjusted rate ratio ( } 95 \% \\
\mathrm{CI})\end{array}$ \\
\hline Non-mini-Holland & $31.0 \%$ & 1 & 1 \\
\hline Mini-Holland & $38.4 \%$ & $1.19(1.03,1.37)^{*}$ & $1.18(1.03,1.36)^{*}$ \\
\hline Non-mini-Holland & $31.0 \%$ & 1 & 1 \\
\hline Waltham Forest & $40.7 \%$ & $1.21(1.02,1.44)^{*}$ & $1.21(1.02,1.45)^{*}$ \\
\hline Kingston & $39.1 \%$ & $1.22(1.01,1.47)^{*}$ & $1.21(1.00,1.46)^{*}$ \\
\hline Enfield & $33.9 \%$ & $1.11(0.88,1.40)$ & $1.10(0.87,1.39)$ \\
\hline Non-mini-Holland & $31.0 \%$ & 1 & 1 \\
\hline Low-dose Mini-Holland & $35.9 \%$ & $1.17(0.99,1.40) \dagger$ & $1.20(1.00,1.42)^{*}$ \\
\hline High-dose Mini-Holland & $41.1 \%$ & $1.20(1.02,1.41)^{*}$ & $1.17(0.99,1.38) \dagger$ \\
\hline$\geq 5 \mathrm{~km}$ from routes & $31.2 \%$ & 1 & 1 \\
\hline $2-4.9 \mathrm{~km}$ from routes & $38.4 \%$ & $1.22(1.00,1.48)^{*}$ & $1.23(1.01,1.50)^{*}$ \\
\hline$<2 \mathrm{~km}$ from routes & $37.6 \%$ & $1.16(0.99,1.36) \dagger$ & $1.14(0.97,1.34)$ \\
\hline Change per km decrease in distance from routes ( $\mathrm{MH}$ group only) & - & $1.01(0.95,1.07)$ & $1.01(0.94,1.07)$ \\
\hline
\end{tabular}

\section{See footnote to Table A3.}

\section{Appendix 2. Supplementary data}

Supplementary data to this article can be found online at https://doi.org/10.1016/j.jth.2020.100958.

\section{References}

Aldred, R., Elliott, B., Woodcock, J., Goodman, A., 2017. Cycling provision separated from motor traffic: a systematic review exploring whether stated preferences vary by gender and age [Internet] Transport Rev. [cited 2019 Apr 27];37(1):29-55. Available from: https://www.tandfonline.com/doi/full/10.1080/01441647. 2016.1200156.

Aldred, R., 2019. Who caused that congestion? Narrating driving and cycling in a changing policy context [Internet] Travel Behav Soc [cited 2019 Nov 9];16:59-69. Available from: https://www.sciencedirect.com/science/article/pii/s2214367X18302114.

Aldred, R., Croft, J., Goodman, A., 2019. Impacts of an active travel intervention with a cycling focus in a suburban context: one-year findings from an evaluation of London's in-progress mini-Hollands programme [Internet] Transport. Res. Part A Policy Pract [cited 2019 Apr 16];123:147-69. Available from: https://www. sciencedirect.com/science/article/pii/S0965856417314866.

Beukers, E., Bertolini, L., Brömmelstroet, M., 2012. Why Cost Benefit Analysis is perceived as a problematic tool for assessment of transport plans: a process perspective [Internet] Transport. Res. Part A Policy Pract [cited 2019 Apr 27];68-78(1):68-78. Available from: https://www.sciencedirect.com/science/article/ pii/S0965856411001376.

Blečić, I., Canu, D., Cecchini, A., Congiu, T., Fancello, G., 2016. Factors of perceived walkability: a pilot empirical study [Internet]. In: Lecture Notes in Computer Science (Including Subseries Lecture Notes in Artificial Intelligence and Lecture Notes in Bioinformatics). Springer, Cham [cited 2019 Apr 27]. pp. 125-37. Available from: http://link.springer.com/10.1007/978-3-319-42089-9_9.

Castillo-Manzano, J.I., Sánchez-Braza, A., 2013. Can anyone hate the bicycle? The hunt for an optimal local transportation policy to encourage bicycle usage [Internet] Environ. Polit. [cited 2019 Apr 27];22(6):1010-28. Available from: http://www.tandfonline.com/doi/abs/10.1080/09644016.2012.740936.

Chatterjee, K., Sherwin, H., Jain, J., 2013. Triggers for changes in cycling: the role of life events and modifications to the external environment [Internet] J. Transport Geogr. 30, 183-193. https://doi.org/10.1016/j.jtrangeo.2013.02.007. Available from:

Fairnie, G.A., Wilby, D.J.R., Saunders, L.E., 2016. Active travel in London: the role of travel survey data in describing population physical activity [Internet] J Transp Heal [cited 2019 Apr 16];3(2):161-72. Available from: https://www.sciencedirect.com/science/article/pii/S221414051600013X.

Fraser, S.D.L.K., Fraser, S.D., Lock, K., 2011. Cycling for Transport and Public Health [Internet]. Eur J Public Health [cited 2019 Apr 27];21(6):738-43. Available from: https://academic.oup.com/eurpub/article-abstract/21/6/738/493197.

Kaczynski, A.T., Henderson, K.A., 2007. Environmental correlates of physical activity: a review of evidence about parks and recreation [Internet] Leisure Sci. [cited 2019 Apr 27];29(4):315-54. Available from: http://www.tandfonline.com/doi/abs/10.1080/01490400701394865.

Kärmeniemi, M., Lankila, T., Ikäheimo, T., Koivumaa-Honkanen, H., Korpelainen, R., 2018. The built environment as a determinant of physical activity: a systematic review of longitudinal studies and natural experiments [Internet] Ann. Behav. Med. [cited 2019 Apr 27];52(3):239-51. Available from: https://academic.oup. com/abm/article-abstract/52/3/239/4815762. 
McCormack, G.R., Shiell, A., 2011. In search of causality: a systematic review of the relationship between the built environment and physical activity among adults [Internet]. Int. J. Behav. Nutr. Phys. Activ. 8 [cited 2019 Apr 27]. Available from: https://ijbnpa.biomedcentral.com/articles/10.1186/1479-5868-8-125.

Smith, M., Hosking, J., Woodward, A., Witten, K., MacMillan, A., Field, A., et al., 2017. Systematic literature review of built environment effects on physical activity and active transport - an update and new findings on health equity [Internet] Int. J. Behav. Nutr. Phys. Activ. [cited 2019 Apr 27];14(1):158. Available from: https://ijbnpa.biomedcentral.com/articles/10.1186/s12966-017-0613-9.

Stappers, N.E.H., Van Kann, D.H.H., Ettema, D., De Vries, N.K., Kremers, S.P.J., 2018. The effect of infrastructural changes in the built environment on physical activity, active transportation and sedentary behavior - a systematic review [Internet] Health Place [cited 2019 Apr 16];53:135-49. Available from: https:// www.sciencedirect.com/science/article/pii/S1353829217311504.

Sun, G., Oreskovic, N.M., Lin, H., 2014. How do changes to the built environment influence walking behaviors? a longitudinal study within a university campus in Hong Kong [Internet] Int. J. Health Geogr. [cited 2019 Apr 16];13(1):28. Available from: http://ij-healthgeographics.biomedcentral.com/articles/10.1186/1476072X-13-28.

Yang, L., Sahlqvist, S., McMinn, A., Griffin, S.J., Ogilvie, D., 2010. Interventions to promote cycling: systematic review [Internet] BMJ [cited 2019 Apr 17];341(oct18 2):c5293-c5293. Available from: http://www.bmj.com/cgi/doi/10.1136/bmj.c5293.

Zou, G., 2004. A modified Poisson regression approach to prospective studies with binary data. Am. J. Epidemiol. 159 (7), $702-706$. 